\title{
Momentum and scalar transport within a vegetation canopy following atmospheric stability and seasonal canopy changes: the CHATS experiment
}

\author{
S. Dupont ${ }^{1}$ and E. G. Patton ${ }^{2}$ \\ ${ }^{1}$ INRA, UR1263 EPHYSE, 33140 Villenave d'Ornon, France \\ ${ }^{2}$ National Center for Atmospheric Research, Boulder, CO, USA \\ Correspondence to: S. Dupont (sdupont @ bordeaux.inra.fr)
}

Received: 8 January 2012 - Published in Atmos. Chem. Phys. Discuss.: 29 February 2012

Revised: 25 May 2012 - Accepted: 13 June 2012 - Published: 12 July 2012

\begin{abstract}
Momentum and scalar (heat and water vapor) transfer between a walnut canopy and the overlying atmosphere are investigated for two seasonal periods (before and after leaf-out), and for five thermal stability regimes (free and forced convection, near-neutral condition, transition to stable, and stable). Quadrant and octant analyses of momentum and scalar fluxes followed by space-time autocorrelations of observations from the Canopy Horizontal Array Turbulence Study's (CHATS) thirty meter tower help characterize the motions exchanging momentum, heat, and moisture between the canopy layers and aloft.

During sufficiently windy conditions, i.e. in forced convection, near-neutral and transition to stable regimes, momentum and scalars are generally transported by sweep and ejection motions associated with the well-known canopytop "shear-driven" coherent eddy structures. During extreme stability conditions (both unstable and stable), the role of these "shear-driven" structures in transporting scalars decreases, inducing notable dissimilarity between momentum and scalar transport.

In unstable conditions, "shear-driven" coherent structures are progressively replaced by "buoyantly-driven" structures, known as thermal plumes; which appear very efficient at transporting scalars, especially upward thermal plumes above the canopy. Within the canopy, downward thermal plumes become more efficient at transporting scalars than upward thermal plumes if scalar sources are located in the upper canopy. We explain these features by suggesting that: (i) downward plumes within the canopy correspond to large downward plumes coming from above, and (ii) upward
\end{abstract}

plumes within the canopy are local small plumes induced by canopy heat sources where passive scalars are first injected if there sources are at the same location as heat sources. Above the canopy, these small upward thermal plumes aggregate to form larger scale upward thermal plumes. Furthermore, scalar quantities carried by downward plumes are not modified when penetrating the canopy and crossing upper scalar sources. Consequently, scalars appear to be preferentially injected into upward thermal plumes as opposed to in downward thermal plumes.

In stable conditions, intermittent downward and upward motions probably related to elevated shear layers are responsible for canopy-top heat and water vapor transport through the initiation of turbulent instabilities, but this transport remains small. During the foliated period, lower-canopy heat and water vapor transport occurs through thermal plumes associated with a subcanopy unstable layer.

\section{Introduction}

Forests play an important role in biosphere-atmosphere exchanges of momentum, energy, water vapor, carbon dioxide and other trace gases. Understanding these exchanges is important for many environmental applications and for properly representing surface exchange in weather and climate models (Harman, 2012). Conditional analysis of momentum and scalar fields (temperature, water vapor, trace gases) have shown that canopy-atmosphere exchange largely occurs through intermittent ventilation of the canopy air 
space by coherent eddy structures (e.g. Gao et al., 1989; Lu and Fitzjarrald, 1994; Scanlon and Albertson, 2001; Thomas and Foken, 2007a). More precisely, quadrant analysis has shown that momentum fluxes are largely explained by strong sweeps and weak ejections associated with these coherent eddy structures (Finnigan, 2000; Poggi et al., 2004). Timetraces of scalar fields reveal ramp patterns which result from these coherent structures (e.g., Gao et al., 1989; Paw U et al., 1992; Finnigan et al., 2009). Under near-neutral conditions, observations confirm this similarity between momentum and scalar transport over a range of vegetated surface types (Coppin et al., 1986; Chen, 1990). With departure from neutral stability conditions, the mechanisms responsible for momentum and scalar transport seem to differ due to modification of the coherent eddy structure topology (Chen, 1990; $\mathrm{Li}$ and Bou-Zeid, 2011). Across all stability classes, scalarscalar transport dissimilarity has also been observed within the atmospheric boundary layer (ABL) and over vegetation which has been attributed to differences of distribution of scalar sources and sinks (Williams et al., 2007) and to the scalar gradient across the top of the ABL's entrainment zone (Moene et al., 2006).

Coherent eddy structures apparently play a crucial role in momentum and scalar transport. Over homogeneous vegetation canopies, coherent eddy structures have been investigated for years using outdoor and wind-tunnel measurements (e.g., Gao et al., 1989; Paw U et al., 1992; Collineau and Brunet, 1993a,b; Turner et al., 1994; Qiu et al., 1995; Shaw et al., 1995; Brunet and Irvine, 2000; Ghisalberti and Nepf, 2002; Steiner et al., 2011) as well as numerical experiments (Shaw and Schumann, 1992; Kanda and Hino, 1994; Patton et al., 2001; Su et al., 2000; Fitzmaurice et al., 2007; Watanabe, 2004; Dupont and Brunet, 2008; Finnigan et al., 2009). These efforts have contributed substantially to our understanding of canopy-scale organized motions, but most of the analysis has been limited to near-neutral stability conditions. It is thought that these coherent structures scale with vorticity thickness and that the average (or "characteristic") structure can be described as the superposition of two hairpin vortices with strong sweeps (gusts) and weak ejections (bursts) between the hairpin legs (Finnigan et al., 2009). In contrast to "buoyantly-driven" motions (thermal plumes) in free convection, these "shear-driven" structures are generated by processes similar to those occurring in a plane-mixing layer flow (Raupach et al., 1996), where Brunet and Irvine (2000) attempted to extend Raupach et al.'s (1996) mixinglayer analogy to non-neutral atmospheric conditions using a broader data set.

Recent studies indicate that these "shear-driven" coherent eddy structures may not be the sole structure type participating in canopy exchange (e.g. Poggi et al., 2004; Thomas and Foken, 2007b). Dupont and Patton (2012) observed that both seasonally driven canopy morphology evolution and departures from neutral stability can weaken the plane mixinglayer analogy of canopy flow, which can even vanish com- pletely in the weak-wind free convective and strongly stable regimes. Dupont and Patton (2012) speculated that with increasing instability, the "shear-driven" coherent eddy structures may initially coexist with and ultimately be replaced by thermal plumes. This speculation is consistent with $\mathrm{Li}$ and Bou-Zeid's (2011) recent study over natural surfaces (a lake and a vineyard), who also suggested that with increasing instability the transport dissimilarity between momentum and scalars could be explained through modification of the near-neutral surface atmospheric boundary layer's hairpin vortices and hairpin packets and their evolution into upward- and downward-moving thermal plumes. In sparse canopies, Poggi et al. (2004) and Kobayashi and Hiyama (2011) suggested that mixing-layer type structures might also coexist with traditional atmospheric surface layer (ASL) turbulence. Forest heterogeneities at scales similar to canopyheight may further modify the efficiency of those turbulent structures at exchanging momentum (Bohrer et al., 2009). In canopies with large and sparse trunk spaces, the mixinglayer's shear-driven structures might also coexist with welldefined wake structures which develop in the lee of tree stems (Cava and Katul, 2008; Launiainen et al., 2007; Dupont et al., 2012), but with length scales similar to the scale of the individual canopy elements. In stable atmospheric stability conditions, an unstable layer can develop in the lower canopy (Shaw et al., 1988; Jacobs et al., 1994; Dupont and Patton, 2012), generating the potential development of both intermittent, small "shear-driven" type coherent eddy structures at the canopy top and thermal plumes lower in the canopy. Consequently, with seasonal canopy changes and with the diurnal evolution of atmospheric stability, the mechanisms responsible for turbulent momentum and scalar exchange between the canopy and the atmosphere may vary. In order to identify regions of the canopy that participate to the turbulent exchanges with the above canopy, Thomas and Foken (2007a) proposed a classification of the degree of coupling of a canopy through five exchange regimes.

The goal of the present paper is to: (1) further investigate the sensitivity of momentum and scalar transport over a deciduous forest to the thermal stability and to the seasonal changes of the forest, (2) establish whether heat, water vapor and momentum are transported similarly, and (3) characterize the turbulent structures accomplishing momentum and scalar transport. To that purpose, we use measurements from the $30 \mathrm{~m}$ profile tower of the Canopy Horizontal Array Turbulence Study (CHATS) (Patton et al., 2011). Compared to previous studies (e.g., Coppin et al., 1986; Chen, 1990; Thomas and Foken, 2007a; Li and Bou-Zeid, 2011), we investigate momentum and scalar transport: (1) within and above the vegetation from tower with unparalleled sensor density, (2) across two different seasonal periods (with and without leaves) for which scalar source/sink distributions vary accordingly, and (3) across five atmospheric stability regimes (free and forced convection, near-neutral, transition to stable and stable). 
Table 1. Perimeters defining the five stability regimes, where $L$ is the Obukhov length evaluated at the mean canopy height $h$. See Dupont and Patton (2012) for further detail.

\begin{tabular}{lrccccc}
\hline Stability regimes & \multicolumn{3}{c}{ No-leaves } & & \multicolumn{3}{c}{ With-leaves } \\
\hline Free Convection (FrC) & -20 & $\leq h / L<$ & -0.2 & -20 & $\leq h / L<$ & -0.2 \\
Forced Convection (FoC) & -0.2 & $\leq h / L<$ & -0.01 & -0.2 & $\leq h / L<$ & -0.01 \\
Near-Neutral (NN) & -0.01 & $\leq h / L<$ & 0.02 & -0.01 & $\leq h / L<$ & 0.006 \\
Transition to Stable (TS) & 0.02 & $\leq h / L<$ & 0.6 & 0.006 & $\leq h / L<$ & 0.6 \\
Stable (S) & 0.6 & $\leq h / L<$ & 20 & 0.6 & $\leq h / L<$ & 20 \\
\hline
\end{tabular}

Dupont and Patton (2012) analyzed statistical profiles of micrometeorological fields from first- to fourth-moments in great detail following five above stability regimes and two seasonal periods. In this current study, after recalling the main experimental setup (Sect. 2), we present an investigation of momentum, heat and water vapor transport through quadrant and octant analyses (Sects. 3 and 4). The organized turbulent structures are then analyzed through space-time autocorrelations in Sect. 5. Finally, in Sect. 6, we discuss the general behavior of turbulent exchange within the CHATS walnut orchard as impacted by canopy morphology and atmospheric stability.

\section{Method}

\subsection{Experiment}

The CHATS experiment took place in Spring 2007 in one of Cilker Orchard's walnut (Juglans regia) blocks in Dixon, California. The campaign consisted of two intensive measurement periods: one focusing on the walnut trees before leaf-out and another on the walnut trees after leaf-out. The trees were planted in a nearly-square pattern and were all about $25 \mathrm{yr}$ old with an average height $h$ of about ten meters. Before leaf-out, the cumulative PAI (Plant Area Index) was about 0.7, while following leaf-out the PAI increased to about 2.5 , with a lower density in the subcanopy.

A $30 \mathrm{~m}$ tower installed in the block sampled turbulent velocity components and virtual temperature fluctuations simultaneously at: 6 within-canopy levels $(1.5,3.0,4.5,6.0$, $7.5,9.0 \mathrm{~m})$, one canopy-top level $(10.0 \mathrm{~m})$, and 6 abovecanopy levels $(11.0,12.5,14.0,18.0,23.0,29.0 \mathrm{~m})$ using thirteen Campbell Scientific CSAT3 sonic anemometers operating at $60 \mathrm{~Hz}$. Twelve NCAR-Vaisala Hygrothermometers (TRH) operating at $2 \mathrm{~Hz}$ sampled air temperature and relative humidity profiles at the same heights as the CSAT3's, except the $12.5 \mathrm{~m}$ level. Campbell Scientific KH2O Krypton hygrometers sampling at $20 \mathrm{~Hz}$ measured water vapor density fluctuations at 6 levels $(1.5,4.5,7.5,10.0,14.0$, and $23.0 \mathrm{~m})$. All instruments on the tower were intercalibrated at the NCAR calibration facility prior to and following the experiment. Turbulence measurements were quality controlled following standard procedures (Dupont and Patton, 2012).
For a more complete description of the CHATS experiment, we refer the reader to Patton et al. (2011).

The integration time for all statistics is $30 \mathrm{~min}$ for unstable and near-neutral conditions and is $5 \mathrm{~min}$ for stable conditions. This shorter integration time for stable conditions is used to reduce contributions from non-turbulent motions. At all heights, the recorded wind velocity components were rotated horizontally so that $u$ represents the horizontal component along the mean wind direction $x$ deduced at canopy top, $v$ the horizontal component in the transverse $y$-direction, and $w$ the vertical component in the $z$-direction. Statistical variables are classified following five thermal stability regimes defined at the canopy top following the procedure described in Dupont and Patton (2012): free convection (referred hereafter as $\mathrm{FrC})$, forced convection (FoC), near-neutral (NN), transition to stable (TS) and stable (S). Table 1 presents the $h / L$ perimeters defining these stability regimes for the two seasonal periods, where $L$ is the Obukhov length evaluated at the mean canopy height $h$.

In the CHATS experiment, all possible measures were taken to limit the influence of any local or site heterogeneities. More specifically, these measures include locating the tower: (1) centered within a tree row with booms holding the instruments into the row-middle minimizing any direct influence of nearby branches or trunks (i.e. minimizing any potential contribution from dispersive stresses following Poggi and Katul (2008)), and (2) approximately 150 canopy heights downwind from the orchard's southern edge in order to avoid any edge effects on the measurements when focusing on southerly winds. The subcanopy was not sparse enough to observe the long distance edge effects observed by Dupont et al. (2011). In addition, statistics presented in this manuscript include averages over a large number of 30min (unstable and neutral conditions) and 5-min (stable conditions) periods which include a range of wind direction variations, wind speed magnitude, and solar radiation or zenith angle (Dupont and Patton, 2012). This averaging should attenuate possible local effects related to the tower position. We also note that during the experiment, the primary wind direction was not generally aligned with the orchard rows (see Figure 3 in Dupont and Patton, 2012), so micrometeorological effects introduced specifically by the orchard's row structure are not expected; especially since the tree crown was 
nearly closed in the sampling row. Finally, for each stability condition, wind spectra do not exhibit any high frequency peaks related to specific small-scale structures induced by local canopy heterogeneities (Dupont and Patton, 2012). For these reasons, we believe that the results presented in this paper are representative of the general orchard turbulence. It is also important to emphasize that our analysis largely focuses on the statistical trends induced by canopy-state and atmospheric stability as opposed to their absolute magnitude.

\subsection{Flux partitioning}

Characterization of momentum, heat and water vapor transport by organized turbulent structures requires a structure identification method. Quadrant and wavelet analyses are both viable methods, where the philosophy behind both approaches varies (e.g. Thomas and Foken, 2007a). Wavelet analysis presumes that the flow is comprised of a superposition of different structures, each with a specific time scale that can be separated from the other. On the other hand, quadrant analysis illuminates structure associated with the complete flow for a confined space-time interval. Despite their differences, both methods produce similar qualitative behavior of flux partitioning. However, quantitatively, Thomas and Foken (2007a) found discrepancies between these two approaches. Interestingly, Steiner et al. (2011) performed a similar analysis to Thomas and Foken (2007a) and found quantitative agreement between flux contribution estimates from coherent structures using both methods. Therefore, the superiority of either method has not been clearly established. Both methods provide value. In this study, we use quadrant and octant hole analyses to investigate the type of event contributing to the momentum, heat and water vapor fluxes.

\subsubsection{Quadrant analysis}

Quadrant analysis decomposes fluxes into quadrants based upon the sign of the fluctuating quantities contributing to the co-variance (e.g., Willmarth and Lu, 1972). We use a parameter $I_{k}$ to define the quadrants, such that for any quadrant $k$, $I_{k}=1$ when the flux falls into quadrant $k$, and $I_{k}=0$ when it does not. Thus for momentum flux in quadrant $1, I_{1}=1$ when $u^{\prime}>0$ and $w^{\prime}>0$, and $I_{1}=0$ otherwise. The criteria defining each of the four quadrants are presented in Table 2. For simplicity when discussing the quadrants, we will refer to them as Q1, Q2, Q3 and Q4.

At times, it is useful to limit our analysis solely to extreme events. In order to partition the data in this way, we perform a hyperbolic hole analysis following Willmarth and $\mathrm{Lu}$ (1972). In this situation, we redefine the quantity $I_{k}$ by $I_{k \mid H}$, where $I_{k \mid H}=1$ if the event falls into the quadrant $k$ and if the event's magnitude is larger than $H$ times the average flux over the time period at a given height (i.e. $\left|u^{\prime} w^{\prime}\right|>H\left|\left\langle u^{\prime} w^{\prime}\right\rangle\right|$ ). $H$ usually varies between 3 and 4 (Poggi et al., 2004). Here, we use $H=3$ when investigating extreme events.
Time averages of momentum or scalar fluxes occurring in each quadrant $k$ are calculated using:

$\left\langle u^{\prime} w^{\prime}\right\rangle_{k \mid H}=\frac{1}{N} \sum_{t=1}^{N} u^{\prime} w^{\prime} I_{k \mid H}$,

and

$\left\langle w^{\prime} \phi^{\prime}\right\rangle_{k \mid H}=\frac{1}{N} \sum_{t=1}^{N} w^{\prime} \phi^{\prime} I_{k \mid H}$,

respectively. Where, \langle\rangle denotes a time average over $N$ samples. Recall that the averaging period is $30 \mathrm{~min}$ for unstable ( $\mathrm{FrC}$ and $\mathrm{FoC}$ ) and near-neutral conditions and 5 min for stable conditions (TS and S). The prime ' depicts the deviation from the average value, $\phi$ is either the air temperature $t$ or the air specific humidity $q$.

For momentum flux, Q2 and Q4 correspond to ejection $\left(u^{\prime}<0\right.$ and $\left.w^{\prime}>0\right)$ and sweep $\left(u^{\prime}>0\right.$ and $\left.w^{\prime}<0\right)$ motions, respectively. In the literature, scalar Q1 and Q3 fluxes have also been referred to as ejection and sweep motions during unstable conditions (e.g., Chen, 1990; Katul et al., 1997; Thomas and Foken, 2007a; Li and Bou-Zeid, 2011). However, organized motions associated with momentum fluxes are not necessarily the same as those transporting scalars (Böhm et al., 2010), especially in unstable conditions. Therefore in order to eliminate ambiguity, we will hereafter use the terms sweep and ejection motions only for momentum quadrant events, i.e. fast momentum fluid transported downward and slow momentum fluid transported upward, respectively. For scalar fluxes under unstable conditions, Q1 and Q3 events will be referred to as upward and downward plumes.

The magnitude fractions of the momentum and scalar fluxes within quadrant $k$ are computed as:

$F_{k \mid H}^{\tau_{u w}}=\left|\left\langle u^{\prime} w^{\prime}\right\rangle_{k \mid H}\right| / \sum_{k}\left|\left\langle u^{\prime} w^{\prime}\right\rangle_{k \mid H}\right|$

$F_{k \mid H}^{\tau_{w \phi}}=\left|\left\langle w^{\prime} \phi^{\prime}\right\rangle_{k \mid H}\right| / \sum_{k}\left|\left\langle w^{\prime} \phi^{\prime}\right\rangle_{k \mid H}\right|$

The reader is therefore cautioned that the magnitude fractions are presented as the absolute value of the flux in a particular quadrant normalized by the sum of the absolute value of the flux across all four quadrants. This choice permits intercomparison across all stability regimes, however it should be noted that this choice eliminates the sign of the flux and forces the sum over all four quadrants to a value of one.

\subsubsection{Octant analysis}

In an octant analysis, the quadrant decomposition of the momentum flux is further decomposed following the sign of the temperature or water vapor fluctuations in order to establish 
Table 2. Description of quadrant events for momentum $\left(u^{\prime} w^{\prime}\right)$, heat $\left(w^{\prime} t^{\prime}\right)$ and water vapor $\left(w^{\prime} q^{\prime}\right)$ fluxes and their associated event names. For any variable $x: x^{+}$signifies $x^{\prime}>0$, and $x^{-}$signifies $x^{\prime}<0$.

\begin{tabular}{ccccc}
\hline Flux & Quadrant 1(Q1) & Quadrant 2 (Q2) & Quadrant 3 (Q3) & Quadrant 4 (Q4) \\
\hline$u^{\prime} w^{\prime}$ & $\begin{array}{c}u^{+} w^{+} \\
\text {outward interaction }\end{array}$ & $\begin{array}{c}u^{-} w^{+} \\
\text {ejection motion }\end{array}$ & $\begin{array}{c}u^{-} w^{-} \\
\text {inward interaction }\end{array}$ & $\begin{array}{c}u^{+} w^{-} \\
\text {sweep motion }\end{array}$ \\
\hline$w^{\prime} t^{\prime}$ & $\begin{array}{c}w^{+} t^{+} \\
\text {warm upward } \\
\text { plume }\end{array}$ & $\begin{array}{c}w^{-} t^{+} \\
\text {warm downward } \\
\text { motion }\end{array}$ & $\begin{array}{c}w^{-} t^{-} \\
\text {cool downward } \\
\text { plume }\end{array}$ & $\begin{array}{c}w^{+} t^{-} \\
\text {cool upward } \\
\text { motion }\end{array}$ \\
\hline$w^{\prime} q^{\prime}$ & $\begin{array}{c}w^{+} q^{+} \\
\text {humid upward } \\
\text { plume }\end{array}$ & $\begin{array}{c}w^{-} q^{+} \\
\text {humid downward } \\
\text { motion }\end{array}$ & $\begin{array}{c}w^{-} q^{-} \\
\text {dry downward } \\
\text { plume }\end{array}$ & $\begin{array}{c}w^{+} q^{-} \\
\text {dry upward } \\
\text { motion }\end{array}$ \\
\hline
\end{tabular}

whether temperature and water vapor are transported similarly as momentum. The same approach was used by Böhm et al. (2010) and van Gorsel et al. (2010). Hence, the momentum flux in quadrant $k\left(\left\langle u^{\prime} w^{\prime}\right\rangle_{k \mid H}\right)$ can be decomposed as:

$\left\langle u^{\prime} w^{\prime}\right\rangle_{k \mid H}=\left\langle u^{\prime} w^{\prime}\right\rangle_{k \mid H}^{\phi^{+}}+\left\langle u^{\prime} w^{\prime}\right\rangle_{k \mid H}^{\phi^{-}}$

where $\phi$ is either $t$ or $q$, and ${ }^{\phi^{+}}$or $\phi^{-}$refers to whether the instantaneous momentum flux coincides with positive or negative $\phi$ fluctuations.

The magnitude fractions of momentum flux in quadrant $k$ coincident with positive and negative $\phi$ fluctuations are calculated using:

$F_{k \mid H}^{\tau_{u w} \mid \phi^{+}}=\left|\left\langle u^{\prime} w^{\prime}\right\rangle_{k \mid H}^{\phi^{+}}\right| / \sum_{k}\left|\left\langle u^{\prime} w^{\prime}\right\rangle_{k \mid H}\right|$

and

$$
F_{k \mid H}^{\tau_{u w} \mid \phi^{-}}=\mid\left\langle\left. u^{\prime} w^{\prime}\right|_{k \mid H} ^{\phi^{-}}\left|/ \sum_{k}\right|\left\langle u^{\prime} w^{\prime}\right\rangle_{k \mid H}\right| .
$$

\subsection{Correlation coefficients between fluxes}

An other method to investigate the similarity between momentum, heat and water vapor fluxes is to look at the correlation coefficients between momentum and scalar fluxes, $r_{u w, w \phi}$, and between heat and water vapor fluxes, $r_{w t, w q}$, which Li and Bou-Zeid (2011) defined as:

$r_{u w, w \phi}=\frac{\left\langle\left(u^{\prime} w^{\prime}-\left\langle u^{\prime} w^{\prime}\right\rangle\right)\left(w^{\prime} \phi^{\prime}-\left\langle w^{\prime} \phi^{\prime}\right\rangle\right)\right\rangle}{\sigma_{u w} \sigma_{w \phi}}$

$r_{w t, w q}=\frac{\left\langle\left(w^{\prime} t^{\prime}-\left\langle w^{\prime} t^{\prime}\right\rangle\right)\left(w^{\prime} q^{\prime}-\left\langle w^{\prime} q^{\prime}\right\rangle\right)\right\rangle}{\sigma_{w t} \sigma_{w q}}$

where $\phi$ is either the air temperature $t$ or the air specific humidity $q, \sigma_{u w}$ and $\sigma_{w \phi}$ are the standard deviation of $u^{\prime} w^{\prime}$ and $w^{\prime} \phi^{\prime}$, respectively.

\subsection{Space-time autocorrelations}

In order to characterize the space and time scales of the structures associated with individual quadrant events, spacetime autocorrelation analysis of streamwise and vertical wind velocity components, temperature and water vapor are performed using:

$R_{\varphi \varphi}^{k \mid H}(T, z)=\frac{\left\langle\left.\left.\left.\varphi^{\prime}\right|_{(0, Z)} \varphi^{\prime}\right|_{(T, z)}\right|_{k \mid H}\right.}{\sqrt{\left\langle\left.\varphi^{\prime 2}\right|_{(0, Z)}\right\rangle_{k \mid H}\left\langle\left.\left.\varphi^{\prime 2}\right|_{(T, z)}\right|_{k \mid H}\right.}}$

where, $\varphi$ refers to one of $u, w, t$ or $q$. Although Eq. (10) can apply generally to any quadrant analysis, our discussion in Sect. 5 will only investigate autocorrelation analyses broken down by heat flux quadrants. Therefore $k$ refers to the heat flux quadrant under consideration (as defined in Table 2 for heat flux). The reference point for the correlation is located at the height $Z$ and at time $T=0$. Statistically, all other levels were sampled with the same indicator mask as the reference level.

The time scale associated with structure for variable $\varphi$ and an individual quadrant event can be deduced from the spacetime autocorrelation at height $Z$ using:

$T_{\varphi \varphi}^{k \mid H}(Z)=0.5 \int_{-\infty}^{+\infty} R_{\varphi \varphi}^{k \mid H}(T, Z) d T$

\section{Momentum transport}

Quadrant analysis (e.g., Willmarth and Lu, 1972) provides information on the motions responsible for momentum transport. Only extreme events are considered in this quadrant analysis $(H=3$ in Eq. 1). These extreme events account for about $55 \%$ to $95 \%$ of the total momentum flux (Fig. S1 in the Supplement), with lower contributions at canopy top and larger contributions with increasing stability and instability.

Figure 1 presents the fraction of $\left\langle u^{\prime} w^{\prime}\right\rangle$ in each quadrant as defined in Eq. (3) for each measurement height partitioned 


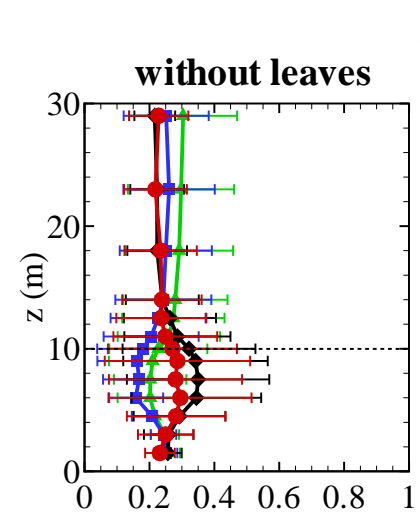

FrC

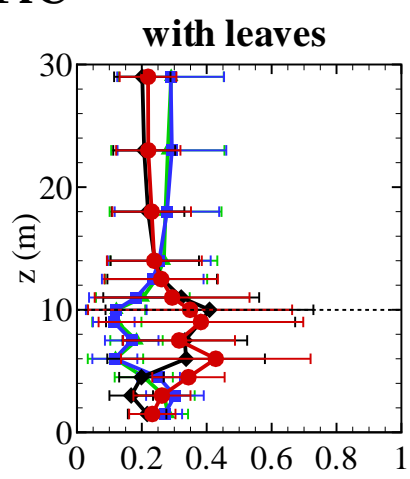

NN
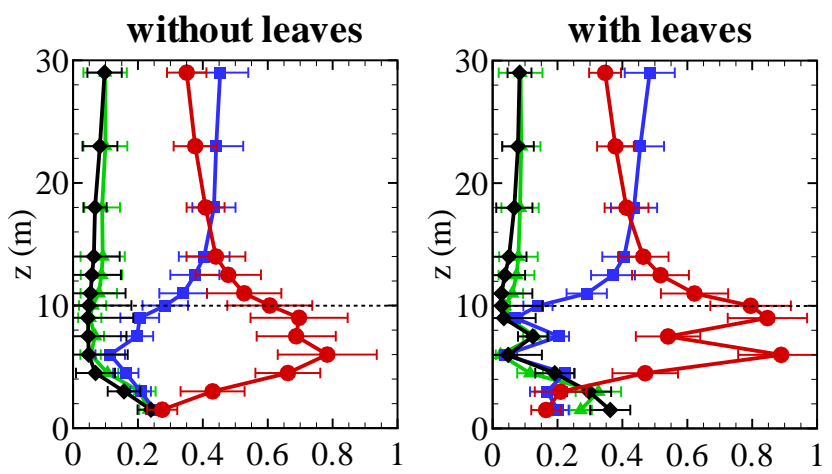

$\mathbf{S}$
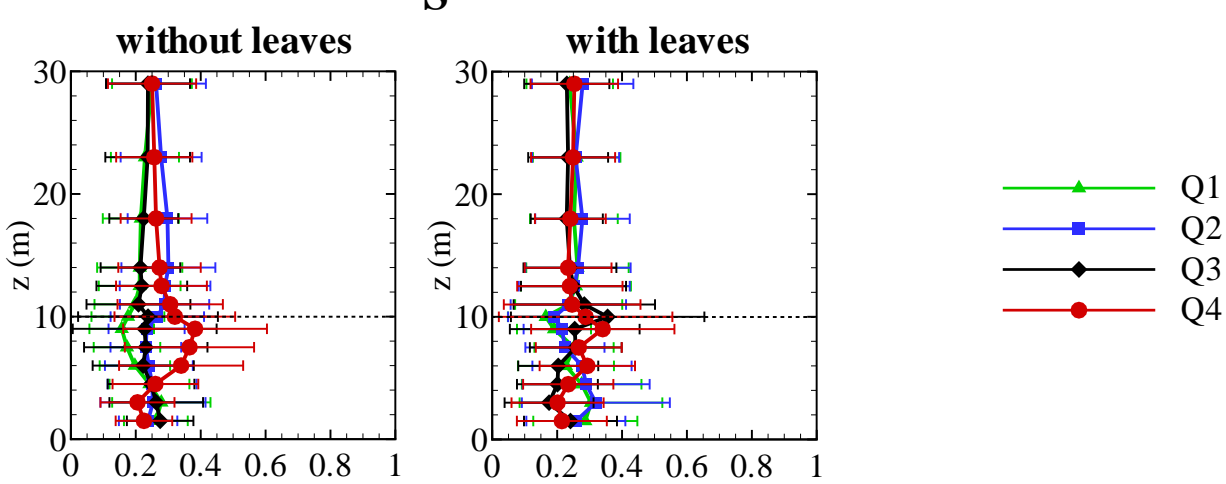

Fig. 1. Fraction of the momentum flux $\left\langle u^{\prime} w^{\prime}\right\rangle$ in each momentum quadrant as defined in Eq. (3) across the three main stability regimes (FrC, $\mathrm{NN}$ and S) and two seasonal periods. Quadrants are defined in Table 2. Error bars indicate the standard deviation of the fractions. The dashed line indicates the canopy top.

according to atmospheric stability and canopy morphology; the error bars depict \pm one standard deviation of the momentum flux contribution in each quadrant, serving as a measure of the variability of each quadrant's contribution at each height.

Consistent with current understanding (e.g., Finnigan, 1979; Shaw et al., 1983), in near-neutral conditions (NN) momentum flux in the upper canopy occurs through a combination of ejections and sweeps, but the majority of momentum transport occurs via sweeping motions (Q4, Fig. 1). During the foliated period, sweeps and ejections transport about $80 \%$ and $15 \%$ of the momentum flux in the upper canopy, respectively, compared with $70 \%$ and $20 \%$ during the period with no-leaves, with standard deviations less than about $10 \%$ during both periods. Furthermore, sweeps dominate momentum transport through the entire canopy during the period with no-leaves, but during the foliated period sweeps only dominate transport in the canopy's foliated region, i.e. above $z / h \sim 0.4$ or $z \sim 4 \mathrm{~m}$; suggesting that the "shear-driven" coherent eddy structures do not penetrate as deeply (i.e. have a smaller vorticity thickness) when the canopy is foliated. Above the canopy, momentum transfer still occurs largely through sweeps and ejections, but ejections dominate above $z / h \sim 1.4$; suggesting a transition of the flow regime from a dominance of the canopy-induced "shear-driven" coherent eddy structures to that of traditional rough-wall boundary layers whose mean wind profile varies logarithmically with height and whose momentum transport has been shown to largely occur through ejection (Q2) motions (e.g., Adrian, 2007). This general feature is in agreement with previous observations over vegetated canopies (Raupach et al., 1996; Finnigan, 2000; Poggi et al., 2004; Dupont and Brunet, 2008) and confirms that under near-neutral conditions momentum transfer at canopy top primarily occurs through the penetration of the canopy by fast, downward-moving gusts.

In free convection ( $\mathrm{FrC})$, the momentum flux is small (see Dupont and Patton, 2012) and its partitioning is nearly equal across the four quadrants; with only $15 \%$ differences between quadrants within the canopy and standard deviations of about the same order of magnitude. In the upper canopy, downward motions dominate momentum transfer during both seasonal periods.

In stable conditions (S), differences between quadrants are less than $10 \%$ throughout the canopy, with standard deviations of about $15 \%$. Sweeps contribute slightly more to upper-canopy momentum transport than the other quadrants 
during the period with no-leaves. However during the foliated period, the distribution is more complex: in the upper canopy, downward motions dominate slightly, while upward motions control momentum transport in the lower canopy. This differing behavior between the lower and upper canopy results from the presence of a well-defined unstable layer in the orchard subcanopy during the foliated period (Dupont and Patton, 2012).

In the intermediate stability regimes (i.e. in the TS and FoC regimes, see Fig. S2 in the Supplement), the momentum flux distribution profiles reveal similar shape to those from the NN regime, but with reduced overall contribution from sweep and ejection motions and compensating larger contributions from inward and outward interactions. These two regimes reveal an intermediate behavior between the NN regimes and their respective extreme stability regimes ( $\mathrm{S}$ and FrC).

In summary, the classic "shear-driven" coherent eddy structures at CHATS (1) appear well defined in the NN regime, especially during the foliated period, (2) are still present in $\mathrm{FoC}$ and TS but weaker for transporting momentum, and (3) are negligible in the extreme $\mathrm{FrC}$ and $\mathrm{S}$ regimes. This result confirms Dupont and Patton's (2012) observations where they showed via analysis of momentum flux correlation coefficients that "shear-driven" coherent eddy structures transport momentum most efficiently during near-neutral conditions.

\section{Scalar transport}

The linkages between turbulent structures and scalar transport at CHATS are now analyzed. In Dupont and Patton (2012) we observed that heat and water vapor sources are distributed similarly during the foliated period (i.e. mostly through the upper canopy and to a lesser extent at the ground) while they differ during the defoliated period (i.e. small and at the ground for water vapor, and large and both at the ground and through the upper canopy for the heat). We suspect that this scalar source distribution variation according to seasonal period should lead to different transport behavior between scalars.

To determine whether the same sweep/ejection events dominating momentum also transport temperature and water vapor, we now extend Sect. 3's quadrant analysis of momentum fluxes using octant analysis (Sect. 4.1). When scalar fluxes are not associated with the same momentum-derived quadrant events, we then use a quadrant analysis of heat and water vapor fluxes to identify the type of events transporting scalars (Sect. 4.2). Finally, flux correlation analysis permits analysis of the similarity between momentum, heat and water vapor fluxes (Sect. 4.3).

\subsection{Momentum flux partitioning and the connection with scalar transport}

As described in Sect. 2.2.2, octant analysis helps identify whether momentum quadrant events transport positive or negative scalar perturbations. For both leaf-states, Figs. 2a and $3 \mathrm{a}$ present octant analyses for temperature fluctuations, where positive and negative fluctuations are denoted by $t^{+}$ and $t^{-}$, respectively.

Because heat fluxes are negligible during NN, one should expect that momentum quadrant events during $\mathrm{NN}$ should correlate with $t^{+}$and $t^{-}$equally. This expectation is wellobserved during the foliated period (Fig. 3a), but Fig. 2a shows that ejections are more correlated with $t^{-}$than $t^{+}$(and the opposite for sweep motions) during the period without leaves. We attribute this discrepancy to the larger number of 30-min periods within the stable side of the NN regime than in the unstable side (see Fig. 4 of Dupont and Patton, 2012).

In the free-convection regime $(\mathrm{FrC})$ and across both seasonal periods, upward motions $(\mathrm{Q} 1$ and $\mathrm{Q} 2)$ correlate more with $t^{+}$and downward motions (Q3 and Q4) more with $t^{-}$ within and above the canopy, which is consistent with the fact that temperature generally decreases with height in unstable conditions. On the other hand, this finding also suggests that heat sources throughout the upper canopy do not change the sign of the temperature fluctuations transported by sweep motions penetrating the canopy. The partitioning of upward (downward) motions between $t^{+}$and $t^{-}$exhibits larger variability for $t^{+}\left(t^{-}\right)$than $t^{-}\left(t^{+}\right)$, which confirms that the correlation of these motions with temperature fluctuations is weakly sensitive to the sign of $u$. The $\mathrm{FrC}$ data also shows that within the upper canopy, downwelling motions correlate more effectively with $t^{-}$than upward motions with $t^{+}$, a feature that is somewhat exacerbated when there are leaves on the trees. We suspect that this feature results from the fact that upwelling motions are largely connected with small-scale convective plumes that are in their infancy developing from canopy-imposed heat sources (either the woody matter or the leaves), while downwelling motions are associated with large ABL-scale convective cells which are able to penetrate through the upper canopy bringing much cooler air from aloft.

In stable condition ( $\mathrm{S}$ ) and across both seasonal periods, upward motions (Q1 and Q2) correlate more with $t^{-}$and downward motions (Q3 and Q4) more with $t^{+}$, from the upper canopy to above, with a maximum at canopy top. Ejection and sweep motions have a slightly larger contribution during the defoliated period. However in the lower canopy during the foliated period, downward motions (Q3 and Q4) correlate more with $t^{-}$and upward motions (Q1 and Q2) more with $t^{+}$. This results from radiative cooling of the upper canopy air by the leaves (which are of low heat capacity) such that downward (upward) motions in the lower canopy layers import relatively cool (warm) air. As in $\mathrm{FrC}$, the variability of the flux partition between $t^{+}$and $t^{-}$confirms that the 


\section{(a) temperature fluctuations}
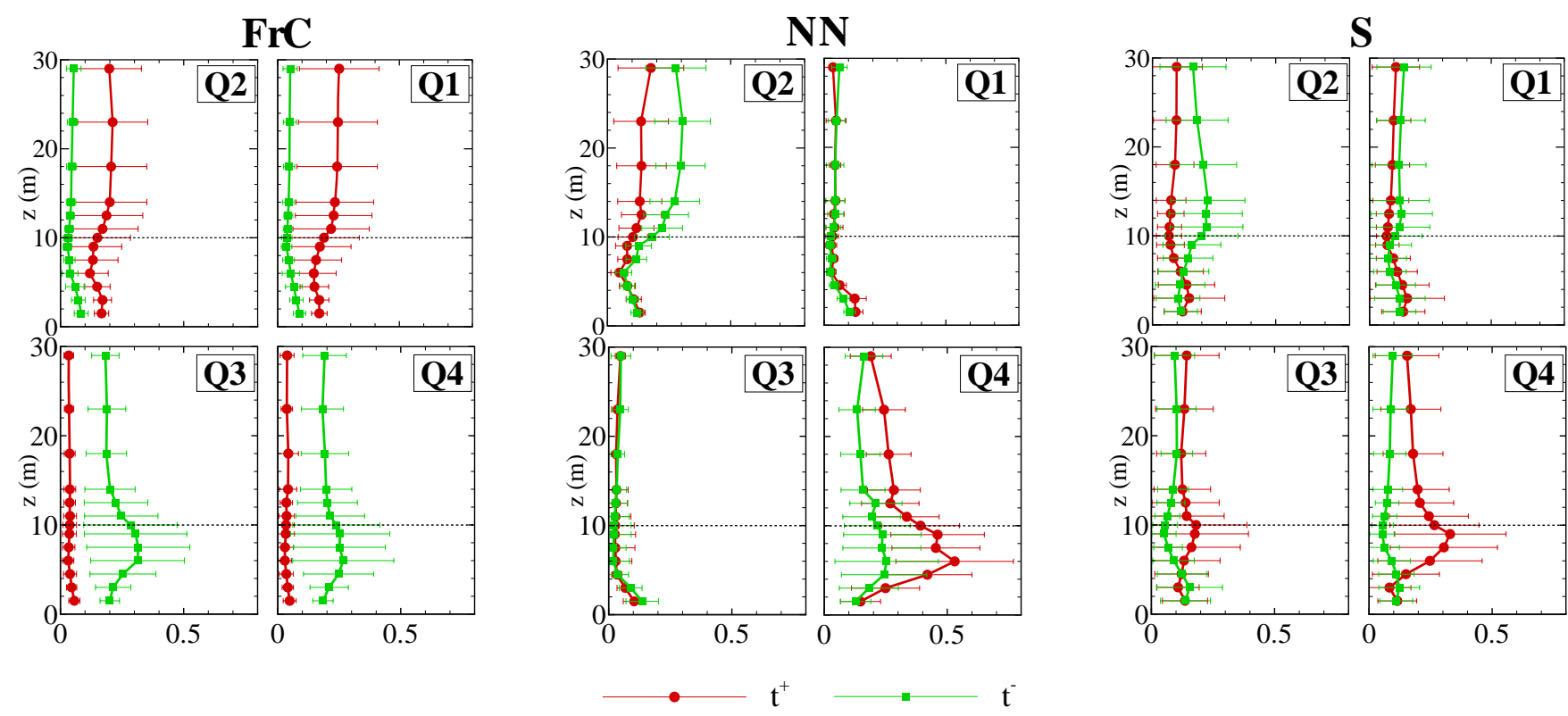

\section{(b) water vapor fluctuations}
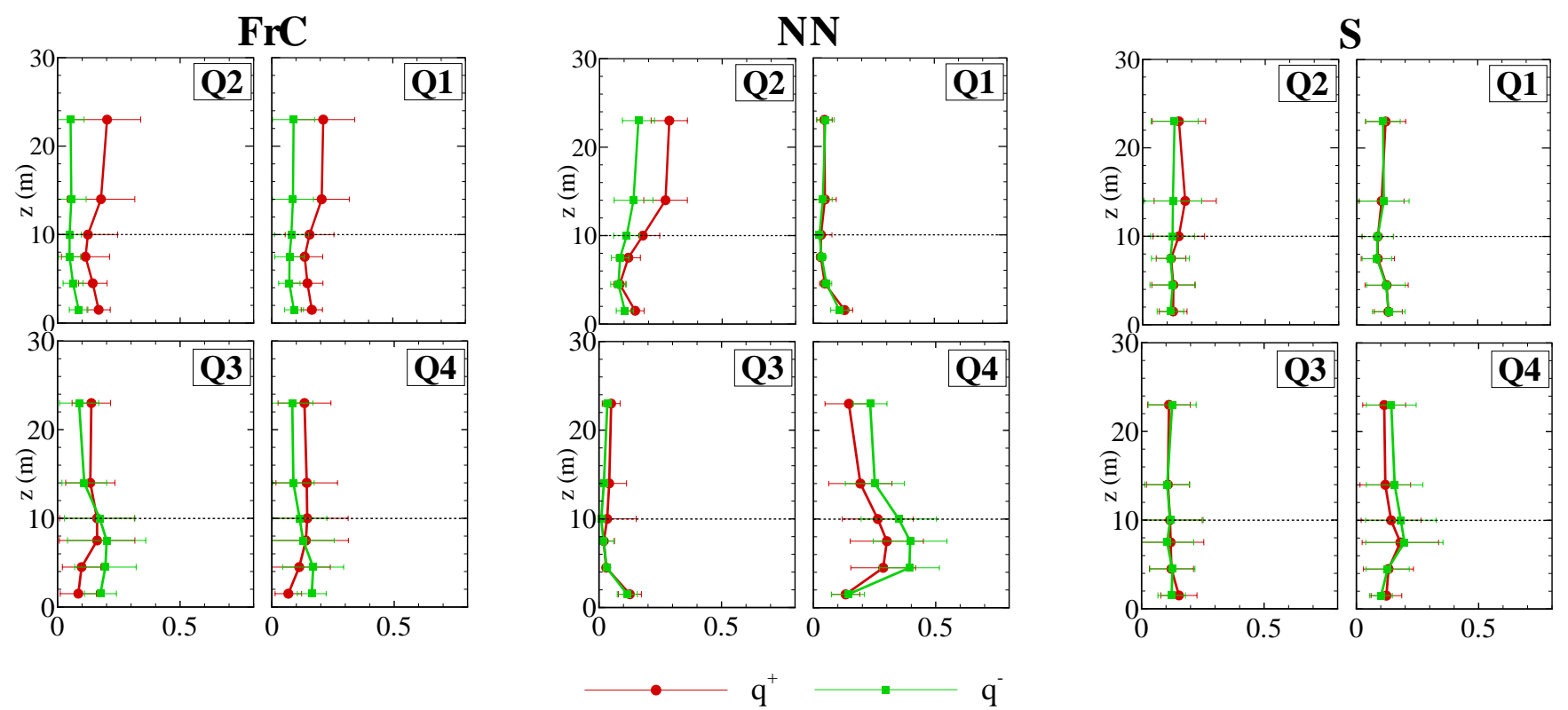

Fig. 2. Fraction of the momentum flux $\left\langle u^{\prime} w^{\prime}\right\rangle$ in each momentum quadrant and associated with positive or negative (a) temperature and (b) water vapor fluctuations, as defined in Eqs. (6) and (7). The three main stability regimes (FrC, NN and S) are presented for the period with no-leaves. The quadrants are defined in Table 2. Error bars indicate the standard deviation of the fractions. The dashed line indicates the canopy top.

correlation of these motions with temperature fluctuations in the lower canopy is weakly sensitive to the sign of $u$.

In the intermediate stability regimes (i.e. TS and $\mathrm{FoC}$, see Figs. S3 and S4 in the Supplement), heat transport conditioned against the four momentum quadrants appears inter- mediate between the NN regime and the extreme stability regimes ( $\mathrm{S}$ and $\mathrm{FrC})$. Ejection motions generally correlate more with $t^{-}\left(t^{+}\right)$during TS (FoC) from the upper canopy up to $29 \mathrm{~m}$, while sweeping motions correlate more with $t^{+}$ $\left(t^{-}\right)$within the canopy during TS (FoC). Outward and inward 


\section{(a) temperature fluctuations}
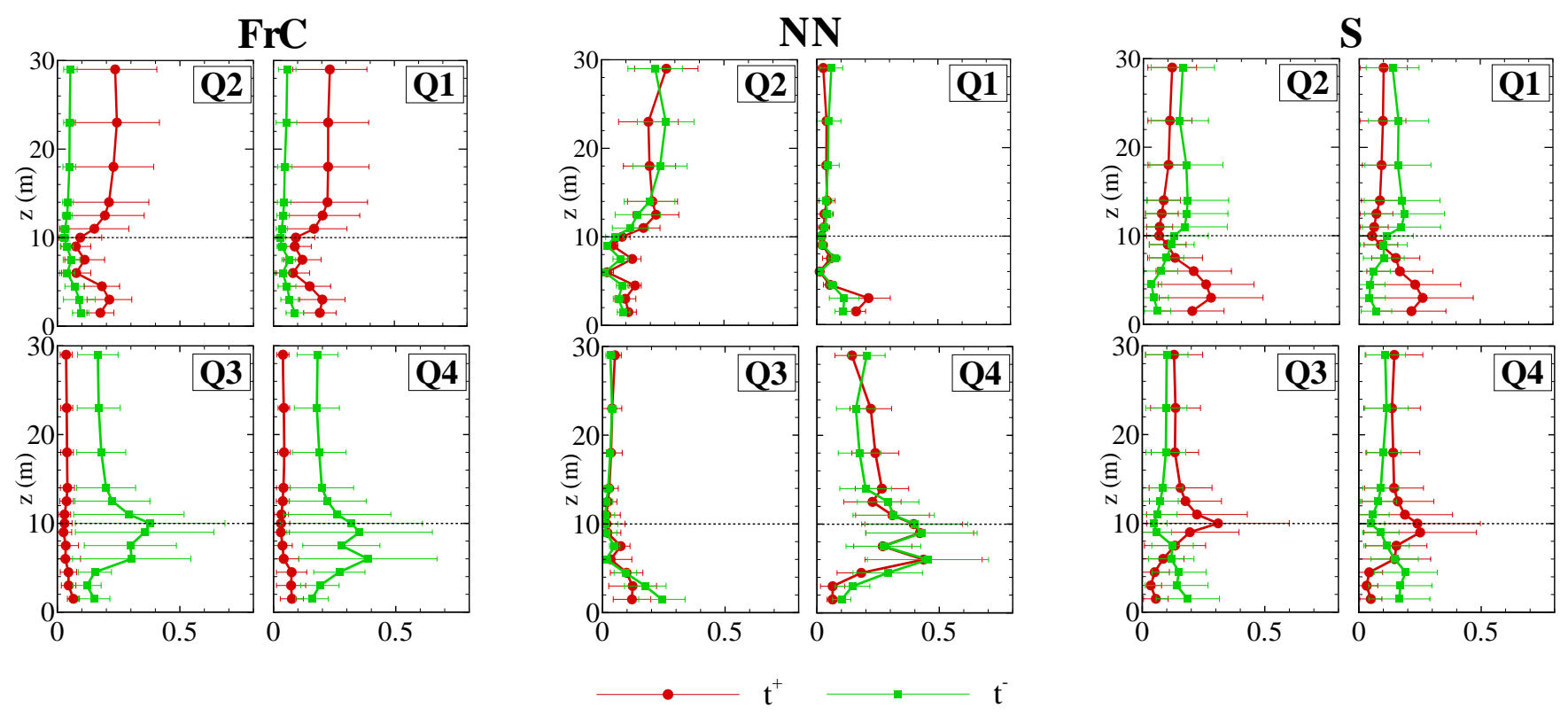

(b) water vapor fluctuations
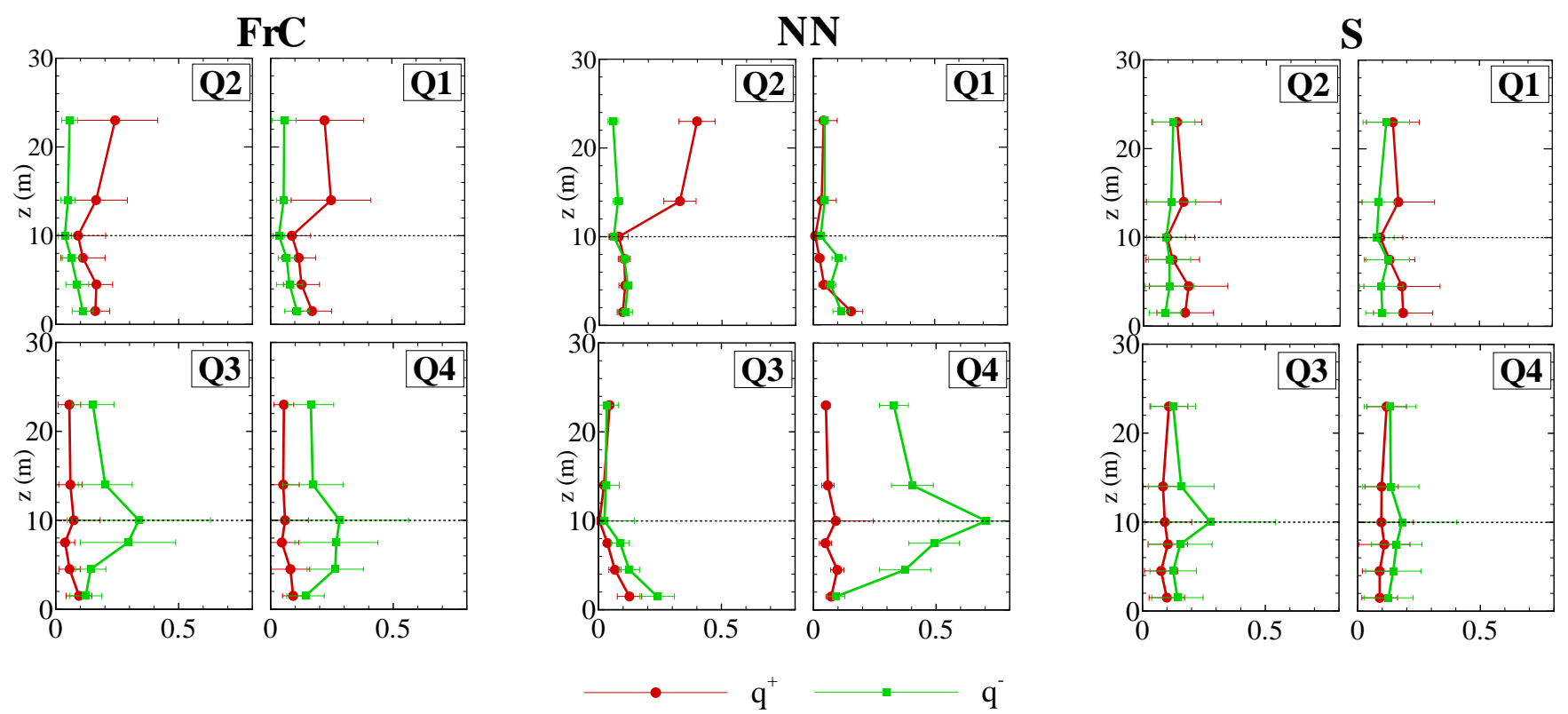

Fig. 3. Same as Fig. 2, but for the period with-leaves.

interaction motions appear slightly more efficient in transporting heat than in NN, especially in FoC and during the foliated period.

The octant analysis for water vapor fluctuations (Figs. 2b and $3 b$ ) exhibits only few differences compared to that for temperature fluctuations. For all stability regimes, upward motions more likely correlate with $q^{+}$and downward motions more likely with $q^{-}$; which results from the generally negative vertical gradient of water vapor in the lower atmosphere (Dupont and Patton, 2012). Similar to that found for heat, negative water vapor fluctuations carried by downward motions are not impacted by crossing water vapor sources in the upper canopy during the foliated period. The uppercanopy source during this period generally increases the efficiency of upward motions at transporting $q^{+}$above the canopy and increases the efficiency of downward motions at 


\section{(a) Heat flux}

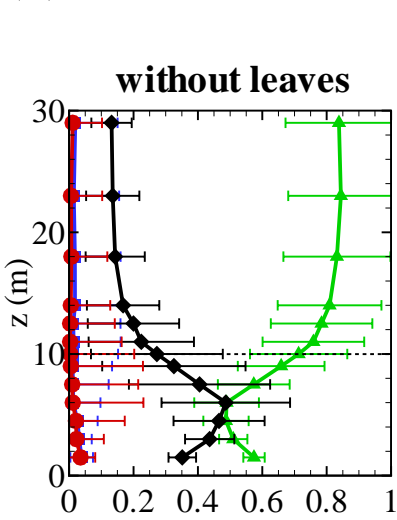

FrC

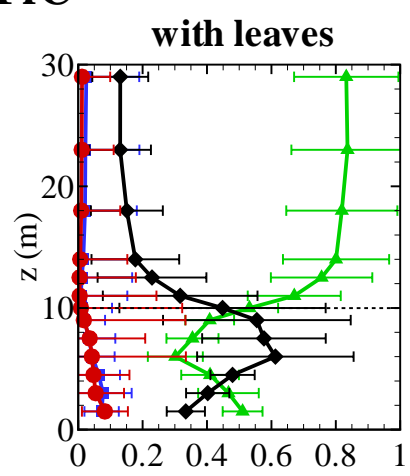

NN
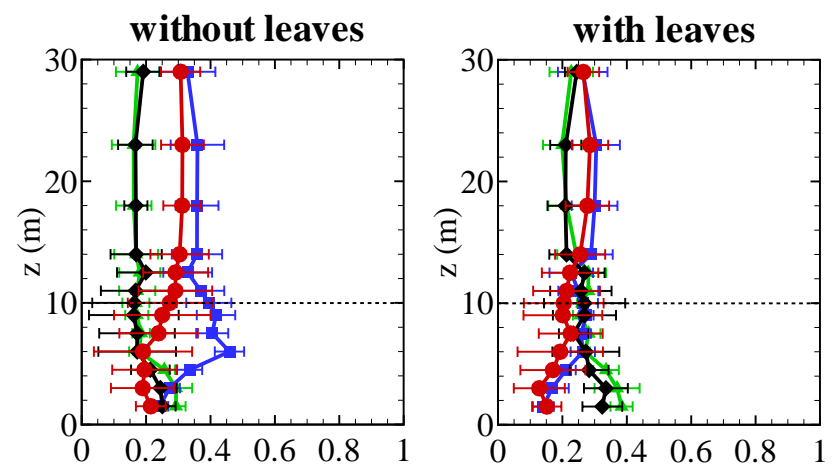

$\mathbf{S}$
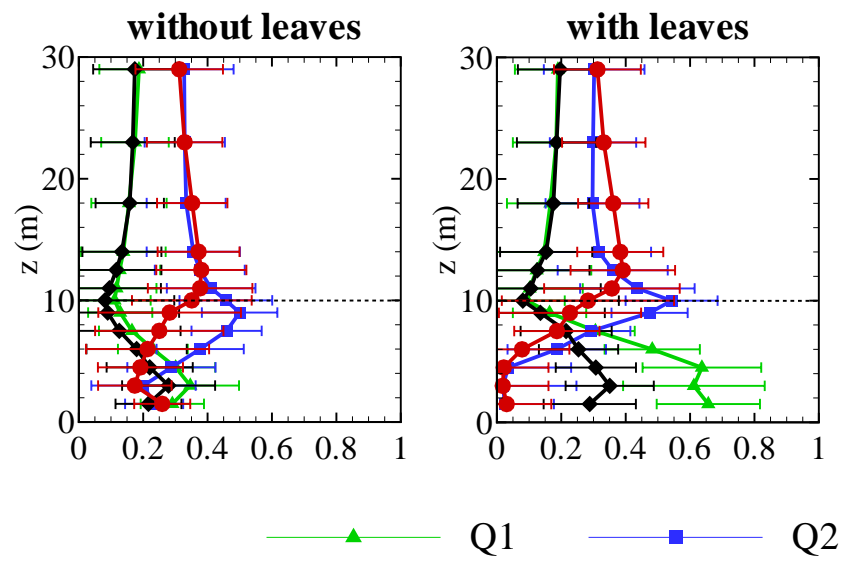

\section{(b) Water vapor flux}

\section{FrC}
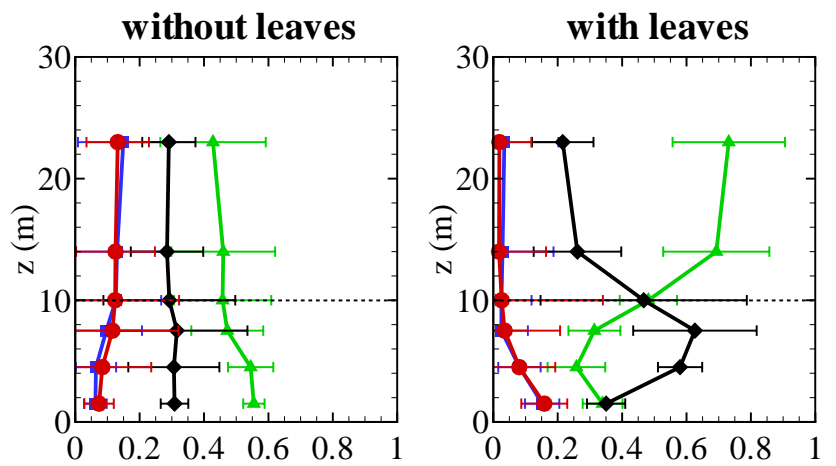

NN
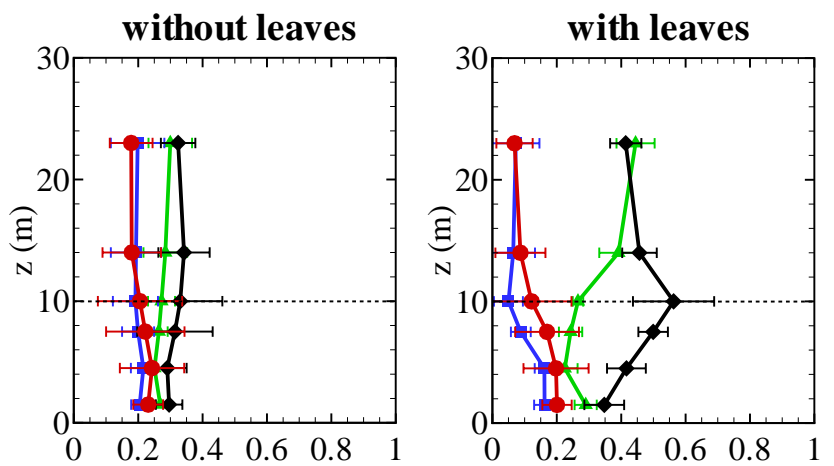

$\mathbf{S}$
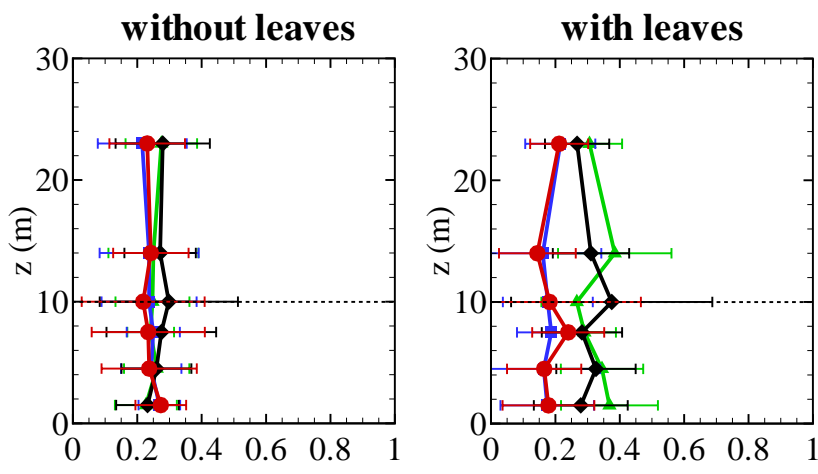

Q4

Fig. 4. Fraction of the (a) heat flux $\left\langle w^{\prime} t^{\prime}\right\rangle$ and (b) water vapor flux $\left\langle w^{\prime} q^{\prime}\right\rangle$ in each quadrant as defined in Eq. (4) for the three main stability regimes (FrC, $\mathrm{NN}$ and $\mathrm{S}$ ) and the two seasonal periods. The quadrants are defined in Table 2. Error bars indicate the standard deviation of the fractions. The dashed line indicates the canopy top.

transporting $q^{-}$in the upper canopy. This result is consistent with Dupont and Patton's (2012) correlation coefficient analysis which suggested increased water vapor transport efficiency when emitted through the upper canopy (foliated period) than at the ground (defoliated period).
It follows from this octant analysis that sweeps and ejections, i.e. "shear-driven" coherent eddy structures, play a major role in transporting scalars in the FoC, $\mathrm{NN}$ and TS regimes, while in $\mathrm{FrC}$ and $\mathrm{S}$ regimes upward and downward motions seem more important. Organized structures 
transport scalars more efficiently if the source is distributed through the upper canopy than if the source is at the surface. Furthermore, scalars carried by downward motions do not seem impacted by crossing scalar sources. More precisely, downward motions appear more efficient at transporting dry and cool air within the canopy in unstable conditions than upward motions at transporting humid and warm air, even well below the main water vapor and heat sources. These different features indicate important information on scalar sources as well as on the different characteristics between downward and upward motions in unstable conditions.

\subsection{Quadrant analysis of scalar fluxes}

In free convection $(\mathrm{FrC})$ and stable $(\mathrm{S})$ conditions, Fig. 1 showed that sweeps and ejections do not contribute significantly more to momentum transfer than inward and outward interactions. To establish whether heat and water vapor fluxes behave similarly to momentum, Fig. 4 shows a quadrant hole analysis of extreme heat and water vapor flux events $(H=3)$ for both seasonal periods and for the three main stability regimes (i.e. FrC, $\mathrm{NN}$ and $\mathrm{S}$; $\mathrm{FoC}$ and TS regimes are presented in Fig. S5 in the Supplement). Contributions to heat and water vapor fluxes from extreme events $(H=3)$ range from $45 \%$ to $95 \%$ with a minimum at canopy top and decreasing magnitude with increasing instability (see Fig. S1 in the Supplement).

\subsubsection{Above the canopy}

Above the canopy, the turbulent heat flux in stable conditions (S) mostly occurs through upward motions carrying cool air (Q4) and secondly by downward motions carrying warm air (Q2). While in unstable conditions ( $\mathrm{FrC})$, the turbulent heat flux occurs through upward motions carrying warm air (Q1) and then secondly by downward motions carrying cool air (Q3). However the opposite is true with regards to the frequency of each quadrant's extreme event occurrence (not shown), i.e. (i) in stable conditions (S) warm downward motions occur more frequently than cool upward motions, and (ii) in free-convective conditions $(\mathrm{FrC})$ cool downward motions occur more frequently than warm upward motions. As conditions shift from forced (FoC) to free convection $(\mathrm{FrC})$, warm upward motions increasingly dominate heat transport, while for increasingly stable conditions (from TS to S) the amplitude difference between warm downward and cool upward motions decreases slightly. We attribute the relative increase of Q1 vs. Q3 in unstable conditions compared to the more similar magnitudes of Q4 vs. Q2 in stable conditions to the fact that under unstable conditions, convective plumes impart vertical asymmetry in the buoyancy forcing. Updrafts confined to narrow regions efficiently transport locally-sourced heat upward, in the direction of the buoyancy forcing, and downdrafts are spatially much broader and weaker transporting heat entrained from above the $\mathrm{ABL}$ less-efficiently downward against the buoyancy forcing (e.g., Wyngaard and Brost, 1984; Schmidt and Schumann, 1989). This more-efficient upward scalar transport by convective plumes is consistent with previously reported in observations above natural and urban surfaces (e.g., Maitani and Ohtaki, 1987; Chen, 1990; Moriwaki and Kanda, 2006; Li and BouZeid, 2011).

Across all stability regimes, above-canopy turbulent water vapor fluxes also occur mostly through humid upward motions (Q1) and dry downward motions (Q3) (Fig. 4b), where Q1 and Q3 events dominate most prominently during the foliated period. During the defoliated period, the abovecanopy water vapor flux partitioning across quadrants varies less with height compared to during the foliated period. We purport that this seasonal quadrant partition variation results from the spatial variation in water vapor source locations between the two periods (i.e. at the ground for the defoliated period, and distributed through the canopy for the foliated period).

\subsubsection{Within the canopy}

During both seasonal periods in unstable conditions ( $\mathrm{FrC})$, a switch occurs between the quadrant events responsible for heat transport above the canopy and within; where this switch occurs both with regards to transport efficiency (Fig. 4a) and to the frequency of occurrence (not shown). Hence, in contrast to the above-canopy findings just discussed, cool downward plumes (Q3 events) dominate within-canopy heat transport, peaking at around $z=6 \mathrm{~m}$ for the defoliated period and shifting up to $z=7 \mathrm{~m}$ in the presence of the leaves. Similarly, the frequency of cool downward plumes (Q3) decreases while that of warm upward plumes (Q1) increases, to even become larger than cool downward plumes (not shown). Similarly, within-canopy water vapor fluxes also switch near canopy-top compared to the above-canopy partitioning (i.e. dry downward plumes (Q3) become more efficient than humid upward plumes (Q1) at transporting water vapor, Fig. 4b). However, this switch only occurs during the foliated period, while during the defoliated period, moist upward plumes (Q1) remain more efficient (or equally efficient) and less frequent than dry downward plumes (Q3) at transporting water vapor. This different behavior for withincanopy water vapor transport (i) with season and (ii) between heat and water vapor during the defoliated period, can only be related to water vapor's differing source distribution between the seasonal periods and to the different source locations of heat and water vapor during the period without leaves, respectively. Note that warm/humid upward (Q1) motions dominate transport in the subcanopy, similar that observed above the canopy.

In stable conditions ( $\mathrm{S}$ ), the importance of warm downward (Q4) motions observed above the canopy rapidly diminishes with depth into the canopy where cool upward motions (Q2) become the main mechanism for transporting heat. 
However, in the lower canopy, warm upward (Q1) and cool downward (Q3) motions accomplish the heat transport due to the layer's unstable air; a feature which is more pronounced during the foliated period. The distribution of turbulent water vapor flux across quadrants does not change much between above and within the canopy.

The TS regime best reveals the leaves' role in modifying the heat and moisture transport mechanisms in the lower canopy (Fig. S5 in the Supplement). When leaves are present under TS conditions, warm upward (Q1) and cool downward (Q3) motions dominate subcanopy transport; but without leaves on the trees for the same stability conditions, subcanopy heat transport largely occurs through warm downward (Q2) motions. After leaf-out, the leaves absorb and reemit a portion of the surface-emitted radiation back toward the surface keeping the surface relatively warm. Therefore upper-canopy leaves exposed to the sky cool faster than the surface generating an unstable subcanopy layer. Hence during the foliated period, heat and water vapor transport in the lower canopy occurs through thermal plumes confined within the canopy extending to between $(4,7) \mathrm{m}$ height during (TS, S) conditions, respectively.

To recapitulate, in free convection $(\mathrm{FrC})$ above-canopy heat and water vapor transport largely occurs through a combination of warm/humid upward (Q1) and cool/dry downward (Q3) motions, providing evidence of convective plumes. While in stable conditions (TS and S), cool/humid upward motions and warm/dry downward motions generally account for their transport. In contrast to these abovecanopy findings associated with unstable conditions, upward and downward motions switch their importance within the canopy in response to the canopy-imposed scalar source. This switch likely relates to the active role of heat inducing small local thermal plumes at the heat source location which also transport water vapor emitted at the same location.

\subsection{Dissimilarity between momentum, heat and water vapor transport}

$\mathrm{Li}$ and Bou-Zeid (2011) recently used correlation coefficients between momentum and scalar fluxes (or scalar-scalar fluxes) to investigate transport similarity/dissimilarity in the atmospheric surface layer above a lake and a vineyard. Although $\mathrm{Li}$ and Bou-Zeid's 2011 analysis yielded important information on the similarity of the various fluxes and their variation with stability, they only had information at a single level. The instrument density on the CHATS tower permits a similar analysis to Li and Bou-Zeid (2011), but with the ability to ascertain the seasonal and vertical canopy variation's influence on stability and transport similarity. Figure 5 presents correlation coefficients between momentum flux and scalar (heat and water vapor) fluxes, $r_{u w, w t}$ and $r_{u w, w q}$, as well as the correlation coefficient between the two scalar fluxes, $r_{w t, w q}$, for both seasonal periods and for the five stability regimes (Eqs. 8 and 9).
Generally speaking, Fig. 5 confirms that the absolute correlations between momentum and scalar fluxes decrease with departures from neutral stability. Absolute correlations between momentum and water vapor fluxes increase during the foliated period for the non-extreme regimes (FoC and TS) because momentum sinks and water vapor sources both largely occur through the canopy, while during the defoliated period water vapor solely comes from the ground. Similarly, $r_{w t, w q}$ increases during the foliated period due to the general colocation of their sources. For all stability regimes, correlations between momentum and scalar fluxes decrease in the lower canopy tending toward zero at the ground.

\section{Characterization of main turbulent structures}

The analysis presented in the previous sections showed that heat and water vapor are generally transported: (1) by warm upward and cool downward thermal plumes in free convection, (2) by sweep and ejection motions in near-neutral conditions, and (3) by warm downward and cool upward motions at canopy top and by warm upward and cool downward thermal plumes in the lower canopy during stable conditions. Since canopy-top sweep and ejection motions during near-neutral conditions have already been discussed in the literature (e.g., Shaw et al., 1983), we now use spacetime autocorrelation analysis to illuminate coherent motion characteristics during the two extreme stability regimes $(\mathrm{FrC}$ and $\mathrm{S}$ ). Space-time autocorrelations have been computed by considering all events $(H=0)$ allowing for the generation of smoother autocorrelation contours, but with similar shape and time scales to those found when restricting the analysis solely to extreme events.

\subsection{Warm upward and cool downward thermal plumes during free convection}

Space-time autocorrelations (Eq. 10) provide information regarding the distance/time over which samples at a fixed location and time are correlated with samples at earlier or later times and other heights on the tower during a particular heat flux quadrant event. For both seasonal periods, Figs. 6-8 present contours of the average space-time autocorrelations of $u, w, t$ and $q$ during free convective conditions ( $\mathrm{FrC}$ ), where events associated with warm upward and cool downward plumes (i.e. Q1 and Q3 for heat flux) are calculated and presented separately. For all three figures, the time reference point is $T=0 \mathrm{~min}$, and the space reference point $Z$ varies for each figure such that: $Z=23 \mathrm{~m}$ (Fig. 6), $Z=10 \mathrm{~m}$ (canopy top, Fig. 7), and $Z=4.5 \mathrm{~m}$ (Fig. 8). For simplicity, we will hereafter refer to space-time autocorrelations from Eq. (10) as $R_{u u}, R_{w w}, R_{t t}$ and $R_{q q}$ for autocorrelations of $u$, $w, t$ and $q$, respectively, and will delineate them according to their association with either warm upward or cool downward plumes. In these figures, negative times correspond to times 

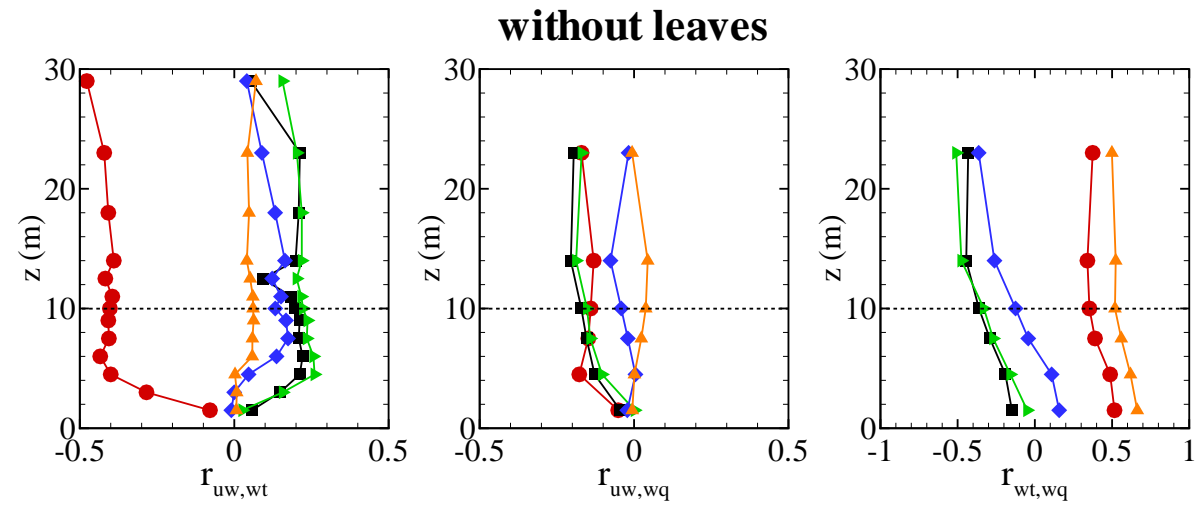

with leaves
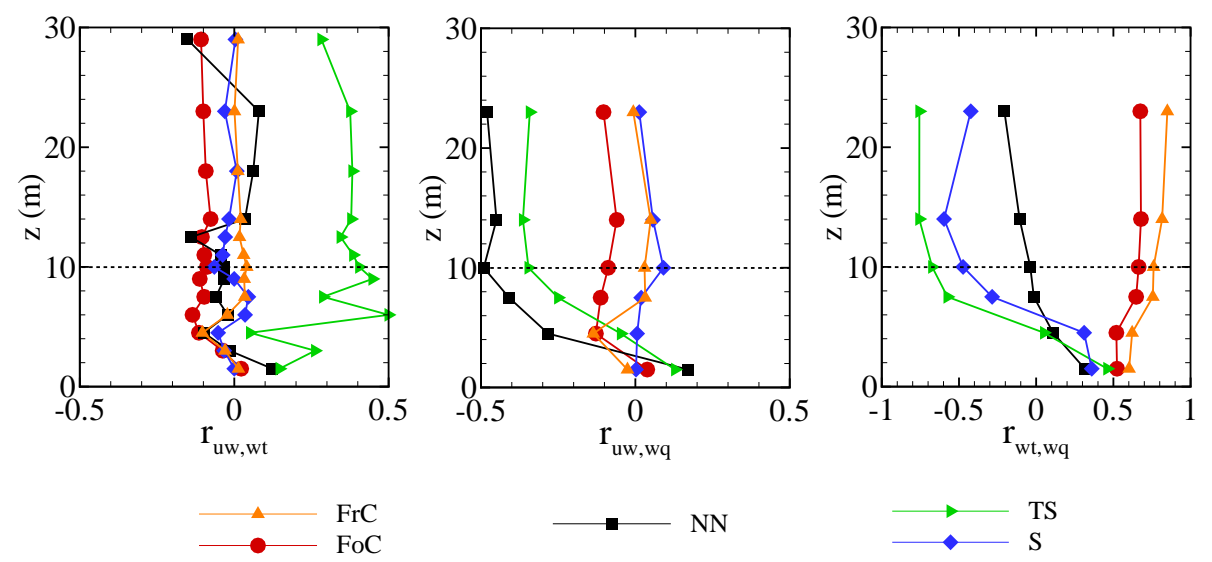

Fig. 5. Vertical profiles of mean correlation coefficients between momentum and heat fluxes $\left(r_{u w, w t}\right)$, momentum and water vapor fluxes $\left(r_{u w, w q}\right)$, and heat and water vapor fluxes $\left(r_{w t, w q}\right)$, for all five stability regimes and for both seasonal periods. The dashed line indicates the canopy top.

before the structure detection (downwind condition) and positive times to times after the structure detection (upwind condition). Note that the time coordinate for $R_{w w}$ spans a shorter duration than the other autocorrelations.

With the reference point located above the canopy at $Z=$ 23 m (Fig. 6), autocorrelation contours of $R_{w w}, R_{t t}$ and $R_{q q}$ indicate that warm upward motions are more connected to within-canopy regions than are cool downward motions, especially during the foliated period. The within-canopy correlations are generally quite low, except for $R_{u u}$ and $R_{q q}$ during the period with no-leaves. Scalar correlation contours (i.e. $R_{t t}$ and $R_{q q}$ ) generally extend upwind for cooldownward plumes and downwind for warm-upward plumes.

With respect to their size and shape, autocorrelations referenced to canopy-top (Fig. 7) reveal distinct differences between the two seasonal periods compared to those referenced above the canopy. $R_{u u}$ and, to a lesser extent, $R_{w w}$ contours appear smaller during the foliated period resulting from the higher canopy density, where (1) the higher canopy density limits downward penetration of the cool-downward motions into the canopy, and (2) the leaves' active contribution may initiate small warm-upward plumes (as discussed in
Sect. 6). $R_{w w}$ contours exhibit generally consistent correlation patterns for both seasonal periods. $R_{u u}$ contours reveal substantially more correlation than $R_{w w}$, but $R_{u u}$ reveals notably shorter time and height correlations for warm-upward motions compared to cool-downward motions. $R_{u u}$ correlations during cool-downward motions tilt distinctly downwind. $R_{t t}$ and $R_{q q}$ contours also tilt downwind, generally extending downwind within and above the canopy for warmupward motions plumes, and extend mostly upwind within the canopy for cool-downward motions. For $R_{t t}$ and $R_{q q}$, cool-downward plumes are also generally correlated over larger depths than are warm-upward motions. As observed for $R_{q q}$ referenced to $Z=23 \mathrm{~m}, R_{q q}$ generally exhibits correlation over longer times and greater depths during the defoliated period compared to the foliated period.

Autocorrelations using a within-canopy reference point ( $Z=4.5 \mathrm{~m}$, Fig. 8 ), $R_{u и}$ contours vertically extend over a significantly shorter distance during the foliated period than during the defoliated period, while the opposite is true for $R_{w w} . R_{t t}$ and $R_{q q}$ correlations reveal quite similar behavior as correlations referenced to canopy top, with the exception that they are more tilted and the former are more 

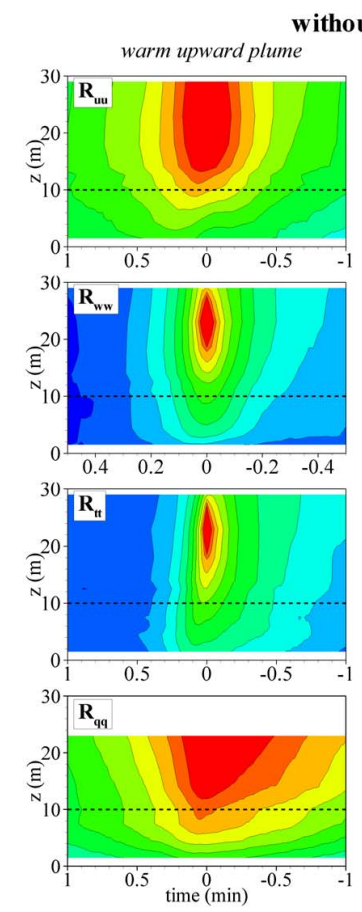
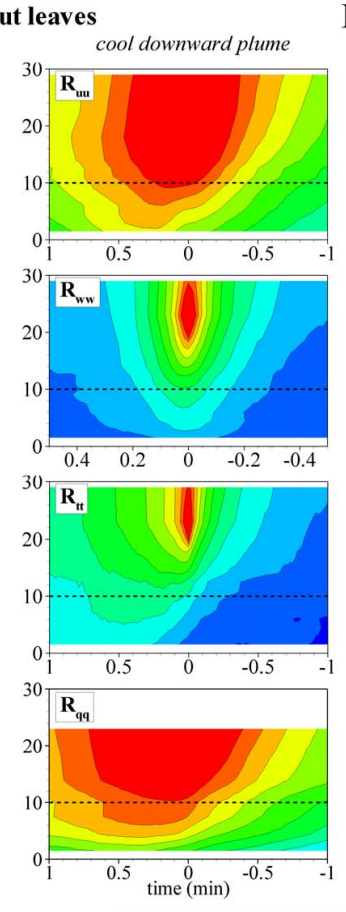

$\begin{array}{lllllllllll}0 & 0.06 & 0.12 & 0.18 & 0.24 & 0.3 & 0.36 & 0.42 & 0.48 & 0.54 & 0.6\end{array}$
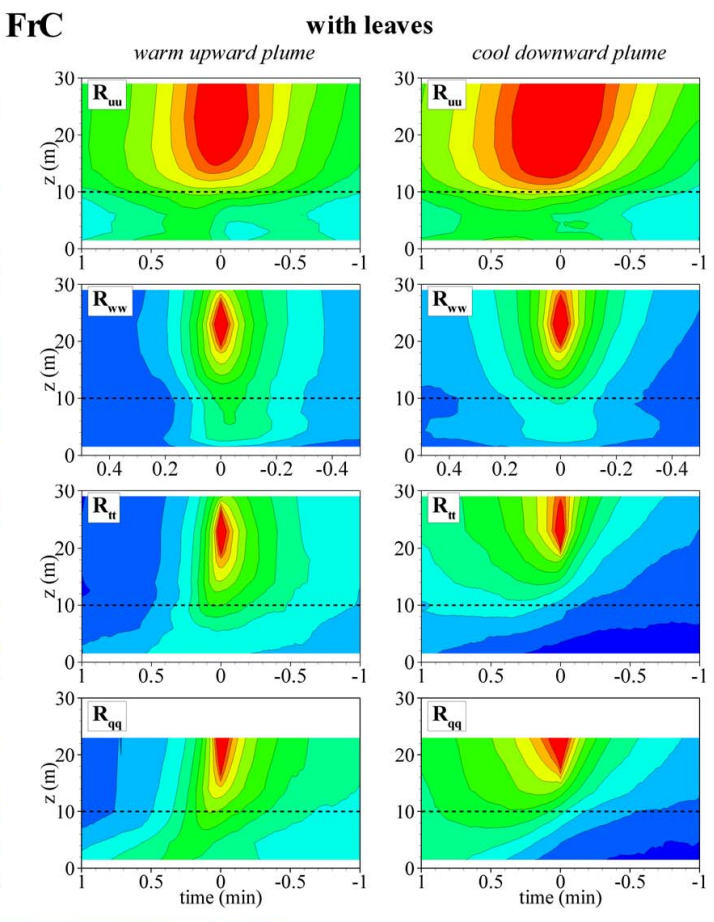

Fig. 6. Autocorrelation contours of $u\left(R_{u u}\right), w\left(R_{w w}\right), t\left(R_{t t}\right)$ and $q\left(R_{q q}\right)$ associated with warm upward and cool downward plumes referenced to $Z=23 \mathrm{~m}$ and $T=0 \mathrm{~min}$, for free convection $(\mathrm{FrC})$ and for both seasonal periods. The autocorrelations correspond to $R_{\varphi \varphi}^{1 \mid 1}$ and $R_{\varphi \varphi}^{3 \mid 1}$ in Eq. (10), where $\varphi$ is either $u, w, t$ or $q$. Negative times correspond to times before the structure detection (downwind condition) and positive times to times after the structure detection (upwind condition). The dashed line indicates the canopy top.

confined within the canopy. Compared to correlations referenced to canopy top, $R_{q q}$ correlations during the period with no-leaves remain significant for cool-downward motions when referenced to $Z=4.5 \mathrm{~m}$, but well correlated contours appear shorter in times and heights for warm-upward motions.

Figure 9a presents time scales $T_{u u}, T_{w w}, T_{t t}$ and $T_{q q}$ associated with warm upward vs. cool downward plumes during FrC for all $Z$. As was observed in the space-time autocorrelations, $T_{u u}$ usually exceeds $T_{t t}$, followed by $T_{w w}$. However during the defoliated period, time scales for $q\left(T_{q q}\right)$ appear larger than those for $u\left(T_{u u}\right)$, and falls between $T_{u u}$ and $T_{t t}$ during the foliated period. Irrespective of the type of motion (warm-upward, or cool-downward), canopy-top mean values of $\left(T_{u u}, T_{t t}, T_{w w}, T_{q q}\right)$ are approximately $(44,14,3,52) \mathrm{s}$ during the defoliated period, and $(25,12.5,3,19.5) \mathrm{s}$ during the foliated period. These $T_{u u}, T_{t t}$ and $T_{w w}$ characteristics are consistent with previous studies which deduced time scales from alternate methods, either lag-correlation (Baldocchi and Meyers, 1988) or wavelet analysis (Collineau and Brunet, 1993b; Thomas and Foken, 2007b). The time-scales obtained here agree particularly well with those observed by Collineau and Brunet (1993b) for slightly unstable conditions over a pine forest, but $T_{t t}$ and $T_{w w}$ are slightly shorter than the time scales presented by Thomas and Foken (2007b) for a range of stability regimes over a spruce canopy in heterogeneous complex terrain. Thomas and Foken (2007b) also observed that scalar (temperature and carbon dioxide) temporal scales were more consistent with those of $u$ than those of $w$, suggesting that lateral scalar transport dominates. Figure 9a shows for CHATS that only $q$ exhibits this feature, especially during the defoliated period.

Compared to those for warm-upward plumes, abovecanopy time scales either appear larger for cool-downward plumes or are nearly identical (Fig. 9a). Within the canopy, time scales are similar for both motion types, except $u$ and $q$ exhibit longer time scales for cool-downward plumes during the defoliated period. $T_{w w}$ and $T_{t t}$ do not change much with leaf-state. On the other hand, $T_{u u}$ increases almost logarithmically with height during the defoliated period, while reducing to a minimum in the upper canopy during the foliated period. $T_{q q}$ follows $T_{u u}$ 's trend during the defoliated period. During the foliated period, $T_{q q}$ also follows $T_{u u}$ 's trend within the canopy, but $T_{q q}$ is intermediate between $T_{t t}$ and $T_{u u}$ above the canopy. The differing behavior between $T_{t t}$ and $T_{q q}$ across seasonal periods most certainly reflects their respective source distribution variations with leaf-state. 

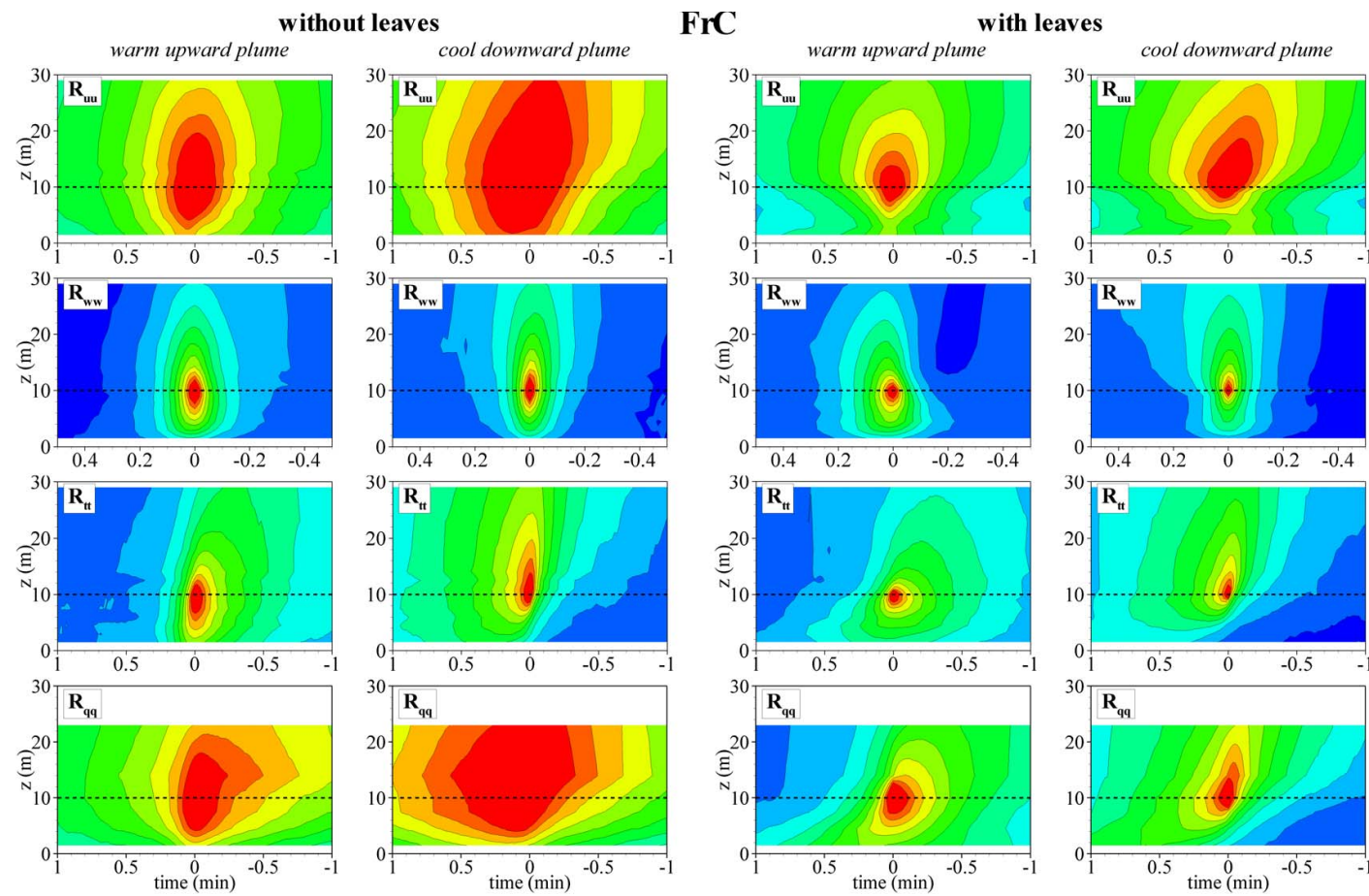

$\begin{array}{lllllllllll}0 & 0.06 & 0.12 & 0.18 & 0.24 & 0.3 & 0.36 & 0.42 & 0.48 & 0.54 & 0.6\end{array}$

Fig. 7. Same as Fig. 6 but for autocorrelations referenced to canopy top ( $Z=10 \mathrm{~m})$.
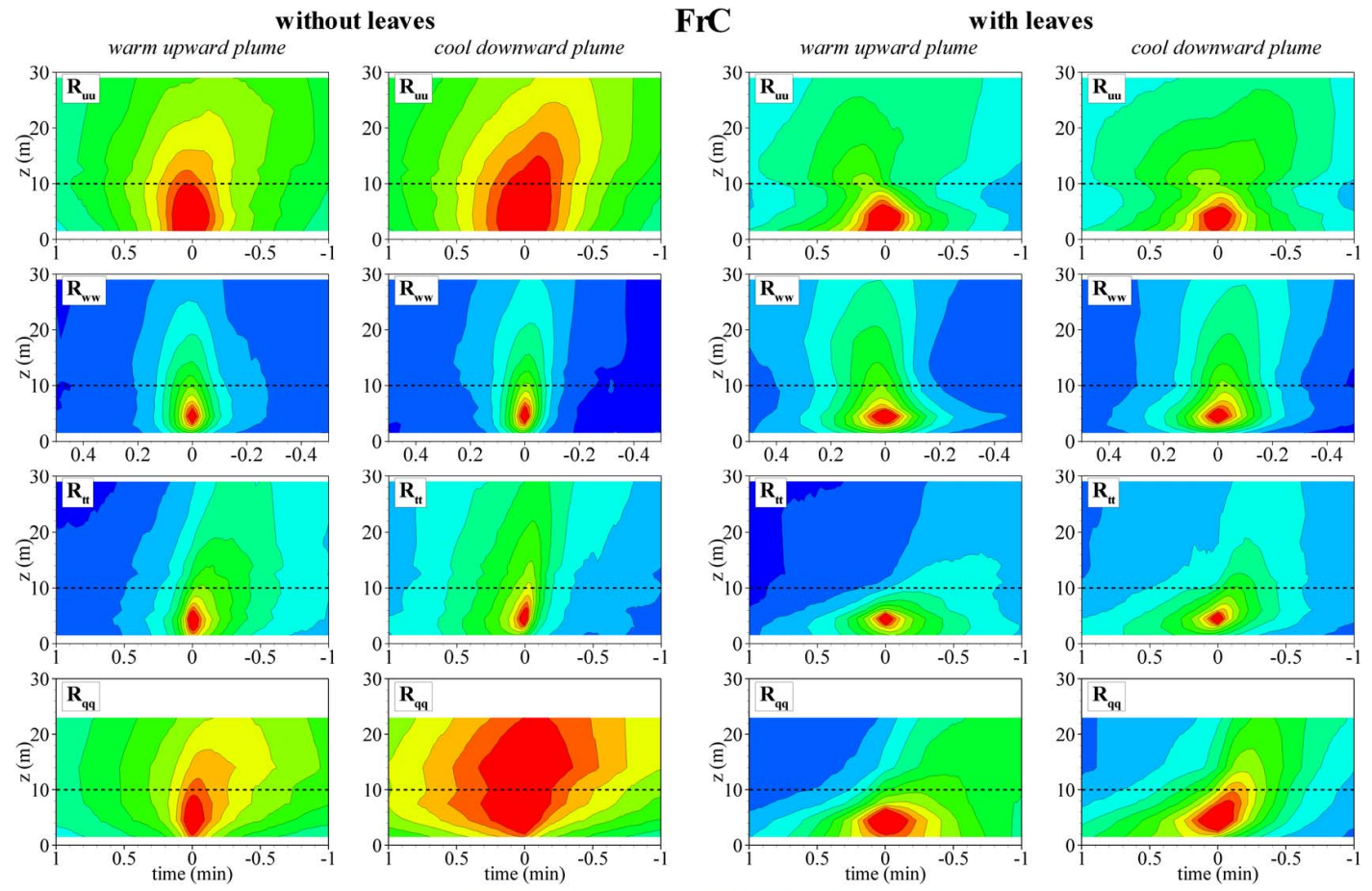

$\begin{array}{lllllllllll}0 & 0.06 & 0.12 & 0.18 & 0.24 & 0.3 & 0.36 & 0.42 & 0.48 & 0.54 & 0.6\end{array}$

Fig. 8. Same as Fig. 6 but for autocorrelations referenced to $Z=4.5 \mathrm{~m}$. 
(a) warm-upward and cool-downward thermal plumes (FrC)
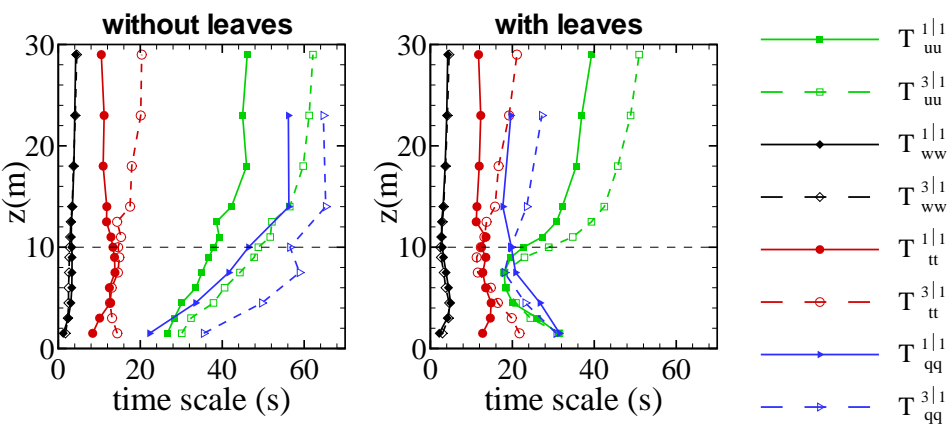

(b) warm-downward and cool-upward motions (S)
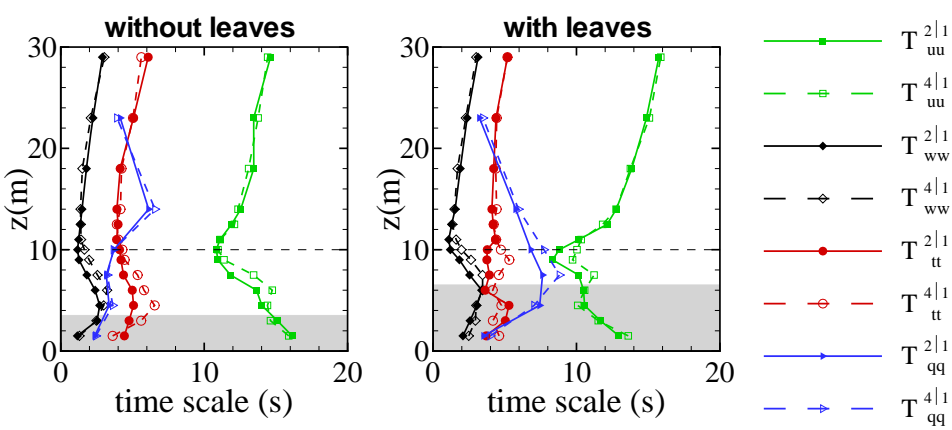

(c) warm-upward and cool-downward thermal plumes (S)

Fig. 9. Temporal scales of $u, w, t$ and $q$ associated with (a) warm upward and cool downward plumes in FrC regime, (b) warm downward and cool upward motions in S regime and (c) warm upward and cool downward plumes in S regime, for both seasonal periods. Note that the temporal scales correspond to (a) $T_{\varphi \varphi}^{1 \mid 1}$ and $T_{\varphi \varphi}^{3 \mid 1}$, (b) $T_{\varphi \varphi}^{2 \mid 1}$ and $T_{\varphi \varphi}^{4 \mid 1}$ and (c) $T_{\varphi \varphi}^{1 \mid 1}$ and $T_{\varphi \varphi}^{3 \mid 1}$ in Eq. (11) with $z=Z$. The dashed line indicates the canopy top and the grey background regions where the motions of interest are not dominant.

\subsection{Warm-downward and cool-upward motions at canopy top during stable conditions}

Contours of $R_{u u}, R_{w w}, R_{t t}$ and $R_{q q}$ in the stable regime (S) for warm downward and cool upward motions referenced to time zero $(T=0 \mathrm{~min})$ and to canopy top $(Z=10 \mathrm{~m})$ are presented in Fig. 10 for both seasonal periods. These correlations correspond to $R_{\varphi \varphi}^{2}$ and $R_{\varphi \varphi}^{4}$ in Eq. (10). Time scales $T_{u u}, T_{w w}, T_{t t}$ and $T_{q q}$ associated with these motions are also presented in Fig. 9b.

$R_{t t}$ and $R_{q q}$ contours indicate that warm-downward motions come from above the canopy as the contours extend higher than those of cool-upward motions and with a downwind tilt elliptical shape. These contours do not extend deep into the canopy, especially during the foliated period, due to (1) the higher canopy density, (2) the stratified layer which develops at canopy top, and (3) the presence of the unstable layer in the lower canopy. On the other hand, $R_{u u}$ and $R_{w w}$ contours do not exhibit significant differences between warm-downward and cool-upward motions. $R_{u и}$ correlates over slightly shorter time and height during the foliated period. Temporal scales (1) appear much shorter compared to those in FrC, except for $T_{w w}$ which is similar, and (2) reveal no significant differences between warm-upward and cool-downward plumes, with the exception of the upper canopy where warm-upward motions have a slightly longer time scales. Consistent with the FrC regime, $T_{q q}$ differs with seasonal period, where during the defoliated period $T_{q q}$ at canopy top is close to $T_{t t}$ and during the foliated period is close to $T_{u u}$.

\subsection{Warm-upward and cool-downward plumes in the lower canopy during foliated stable conditions}

Contours of $R_{u u}, R_{w w}, R_{t t}$ and $R_{q q}$ in the stable regime (S) for warm-downward and cool-upward motions referenced to time zero $(T=0 \mathrm{~min})$ and to the middle canopy $(Z=4.5 \mathrm{~m})$ are presented in Fig. 11 for the period with leaves. These correlations correspond to $R_{\varphi \varphi}^{1}$ and $R_{\varphi \varphi}^{3}$ in Eq. (10). Time scales $T_{u u}, T_{w w}, T_{t t}$ and $T_{q q}$ associated with these motions are also presented in Fig. 9c for the same seasonal period.

Correlated areas generally remain confined to the lower canopy (below $\sim 6 \mathrm{~m}$ ), especially for scalars, indicating a decoupling between the lower- and upper-canopy regions. Contours of $R_{u u}$ and $R_{w w}$ extend slightly above the canopy but mostly on the upwind side suggesting that thermal plumes within the canopy may destabilize the flow above acting probably to generate Kelvin-Helmholtz structures; subtly 

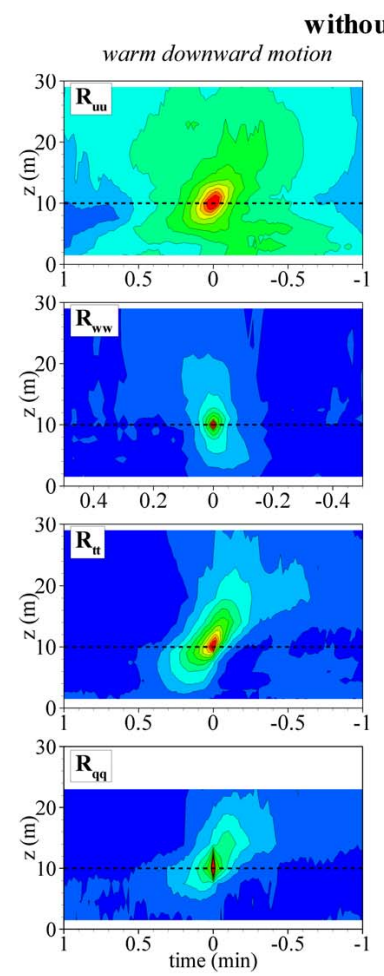

$\mathbf{S}$
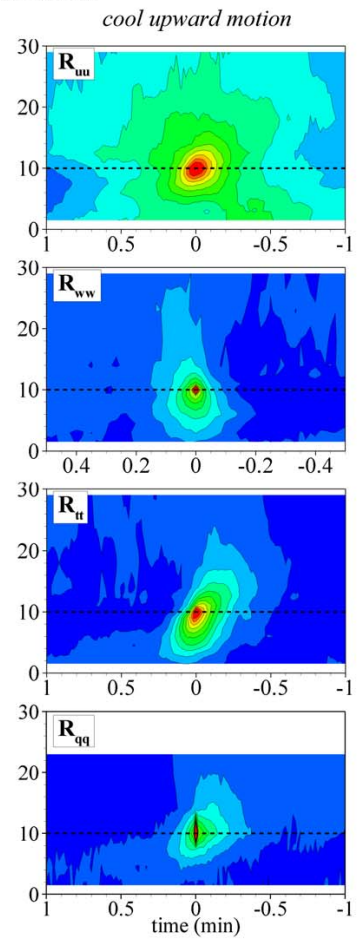
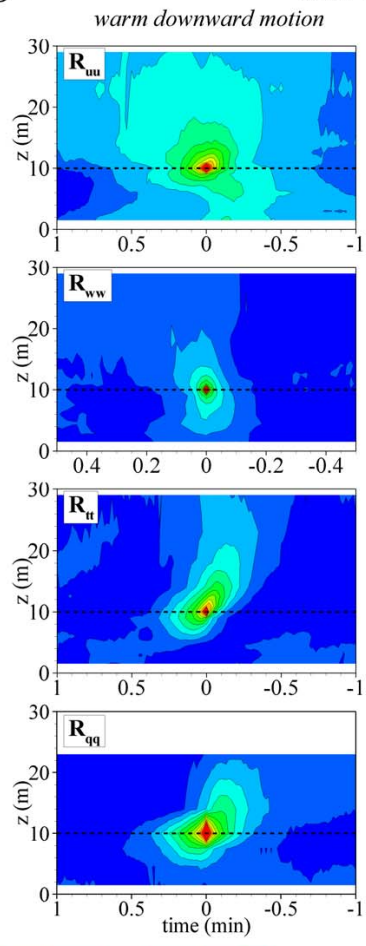

with leaves
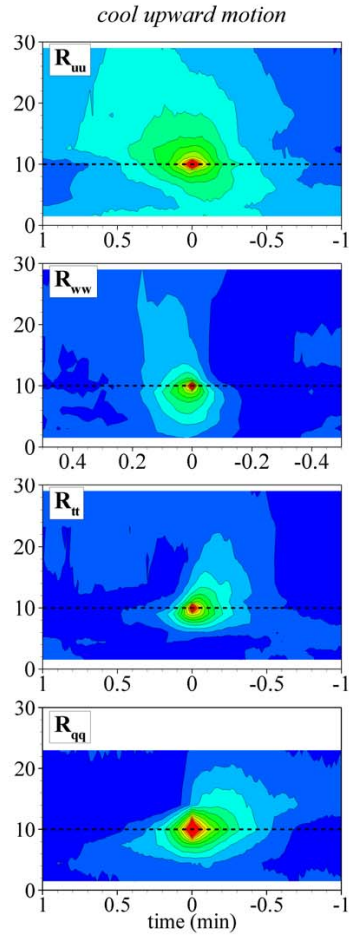

$\begin{array}{lllllllllll}0 & 0.06 & 0.12 & 0.18 & 0.24 & 0.3 & 0.36 & 0.42 & 0.48 & 0.54 & 0.6\end{array}$

Fig. 10. Autocorrelation contours of $u\left(R_{u u}\right), w\left(R_{w w}\right), t\left(R_{t t}\right)$ and $q\left(R_{q q}\right)$ associated with warm downward and cool upward motions referenced to canopy top $(Z=10 \mathrm{~m})$ and $T=0 \mathrm{~min}$, for the stable regime (S) and for both seasonal periods. The autocorrelations correspond to $R_{\varphi \varphi}^{2 \mid 1}$ and $R_{\varphi \varphi}^{4 \mid 1}$ in Eq. (10), where $\varphi$ is either $u, w, t$ or $q$. Negative times correspond to times before the structure detection (downwind condition) and positive times to times after the structure detection (upwind condition). The dashed line indicates the canopy top.

recoupling the lower and upper canopy layers. Contours of $R_{u u}$ and $R_{w w}$ are almost circular within the canopy while contours of $R_{t t}$ and $R_{q q}$ extend more-so upwind for upward plumes and downwind for downward plumes. Time scales $T_{w w}, T_{t t}$ and $T_{q q}$ are comparable within the subcanopy with a maximum around $z=4.5 \mathrm{~m}$ for $T_{w w}$ and $T_{t t}$ and around $z=7 \mathrm{~m}$ for $T_{q q} . T_{u u}$ is larger and increases with height within the canopy. Hence, heat and water vapor should be mostly transported within the subcanopy by active turbulence, probably the local thermal plumes.

\section{Discussion}

Momentum and scalar (i.e. heat and water vapor) transfer between an orchard canopy and the overlying atmosphere has been investigated for two seasonal periods (trees without and with leaves), and for five thermal stability regimes (free and forced convection, near-neutral, transition to stable, and stable). From quadrant and octant analysis of momentum and scalar fluxes, as well as from space-time auto-correlations of wind velocity components and scalars, we are able to identify some characteristics of the turbulent structures transporting such quantities according to the atmospheric stability and leaf state. Figure 12 summarizes these characteristics which are discussed in the following sub-sections.

\subsection{Free convection regime}

In this regime, scalar transport (heat and water vapor) occurs mostly through thermal plumes. Due to low mean wind speeds, shear-driven organized turbulent structures do not exist for momentum transport. Warm/humid upward thermal plumes appear more efficient and less frequent than cool/dry downward thermal plumes at above-canopy heat and water vapor transport. Upward plumes are narrower and more intense than surrounding downward plumes, as indicated by the positive skewnesses of the temperature, water vapor and vertical wind velocity (Dupont and Patton, 2012); a typical feature of convective boundary layers.

Scalar autocorrelations, and to a lesser extent wind velocity autocorrelations, have shown that downward plumes at canopy-top come from above the canopy while upward plumes originate mostly from within the canopy; this feature being especially true during the foliated period. Upward plumes within the canopy were also shown to become less efficient but more frequent at transporting heat than downward 


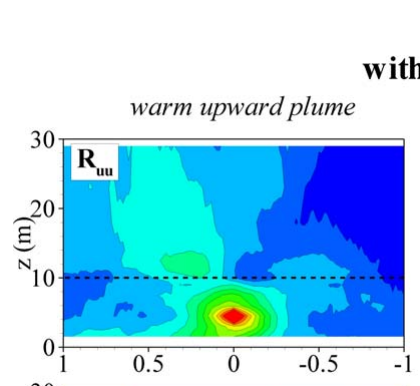

$\mathbf{S}$

with leaves
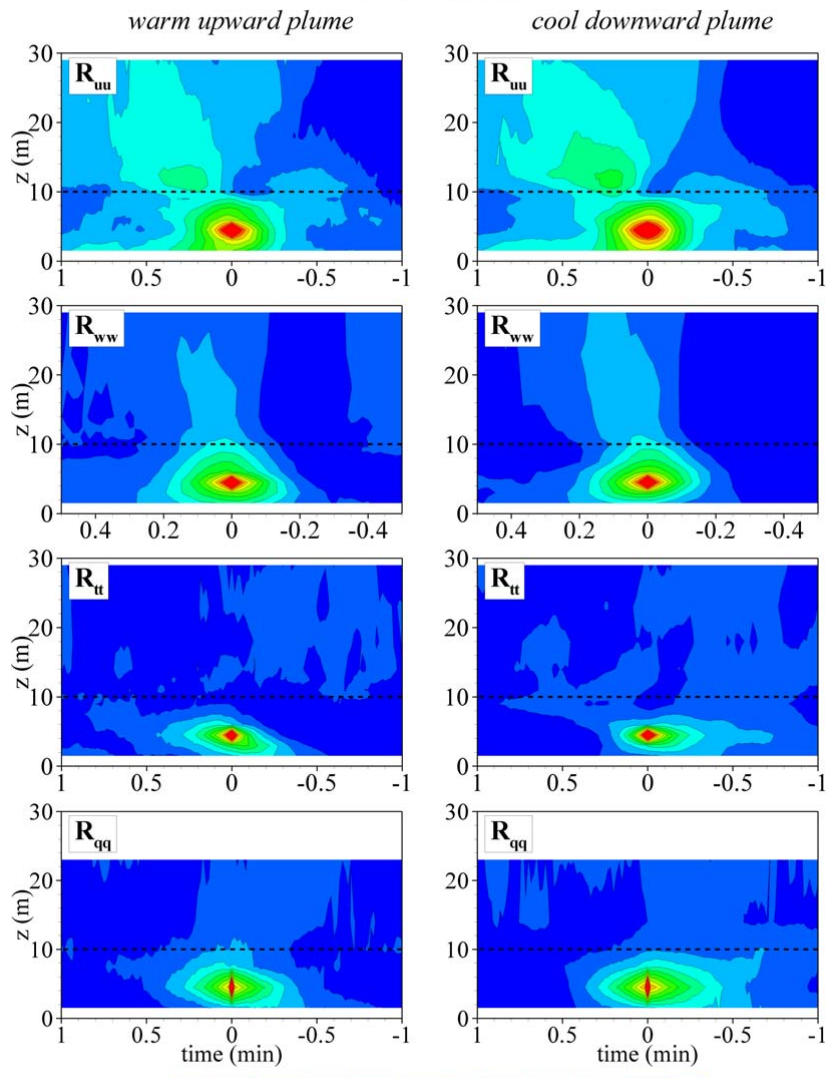

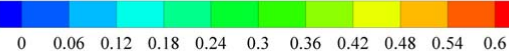

Fig. 11. Autocorrelation contours of $u\left(R_{u u}\right), w\left(R_{w w}\right), t\left(R_{t t}\right)$ and $q\left(R_{q q}\right)$ associated with warm upward and cool downward plumes referenced to the middle canopy $(Z=4.5 \mathrm{~m})$ and $T=0 \mathrm{~min}$, for the stable regime $(\mathrm{S})$ and for the period with leaves. The autocorrelations correspond to $R_{\varphi \varphi}^{1 \mid 1}$ and $R_{\varphi \varphi}^{3 \mid 1}$ in Eq. (10), where $\varphi$ is either $u$, $w, t$ or $q$. Negative times correspond to times before the structure detection (downwind condition) and positive times to times after the structure detection (upwind condition). The dashed line indicates the canopy top.

plumes, although both plumes have comparable time scales. In order to explain these different features, we speculate that large upward plumes of the convective boundary layer do not form at the canopy top but somewhere above the canopy. These large upward thermal plumes likely result from aggregation of local, small, upward thermal plumes induced by canopy-imposed heat sources that actively participate in turbulence; a process which has been previously documented by Gates and Benedict (1963) over broad-leaved and coniferous trees. Hence, we suggest that heat sources imposed by the canopy elements (especially during the foliated period) generate small scale plumes coalescing well above the canopy into large upward thermal plumes. During the period with no-leaves when the heat source from the ground overwhelms that from the upper canopy, large upward plumes may develop closer to the ground; an idea which is supported by the large vertical extent of the correlations within and above the-canopy for upward plumes. This mechanism explains the frequency increase and lower intensity of upward thermal plumes within the canopy compared to above.

Downward plumes within the canopy likely correspond to the downwelling legs of large ABL-scale convective boundary layer plumes penetrating within the canopy. Their penetration attenuates through momentum absorption as these large-scale motions encounter the canopy elements, generating a time lag between their presence at the canopy top and at the ground. Downward plumes appear (1) more efficient at scalar transport, and (2) less frequent than withincanopy upward plumes; a consequence of directly comparing against upward plumes. Upward plumes exhibit different characteristics throughout and above the canopy, while downward plumes remain the same fluid motion within the canopy as found above the canopy, albeit with less vigor as their momentum is partly attenuated by vegetation elements.

During the foliated period, water vapor sources/sinks are similar to those for heat, occurring mostly in the upper canopy where local thermal plumes develop. Consequently, water vapor should be directly injected into these local upward thermal plumes and be transported initially by them; a feature suggesting that heat and water vapor should be transported similarly during the foliated period. However, (1) Dupont and Patton (2012) showed larger correlation coefficients for heat transfer than for water vapor transfer, suggesting that heat is transported more efficiently by organized structures than water vapor, and (2) the temporal scale of the water vapor is slightly larger than that of the temperature but lower than that of the longitudinal velocity. We explain this discrepancy by (1) the dominant role heat plays in generating the local upward thermal plumes (i.e. water vapor's contribution may be regarded as passive compared to heat in free convection), (2) the possible local dissimilarity between heat and water vapor source distribution, and (3) the time response for stomata to open/close (a few minutes according to Jones, 1992) that could generate a phase shift between water vapor release and thermal plume development; all combining to reduce the efficiency of local upward thermal plumes at transporting water vapor.

During the period with no-leaves, water vapor sources occur solely at the ground while heat sources occur both at the ground and through the canopy. Local upward thermal plumes induced by upper-canopy heat sources may not transport much water vapor, since water vapor is released at the surface and not directly within in these plumes; which is confirmed by the fact that water vapor's temporal scale is notably longer than temperature's with temporal scales more like the longitudinal wind velocity within and above the canopy. When water vapor is emitted solely at the surface, within-canopy upward motions transport more water vapor than do within-canopy downward plumes; with this 
(a) Free convection regime
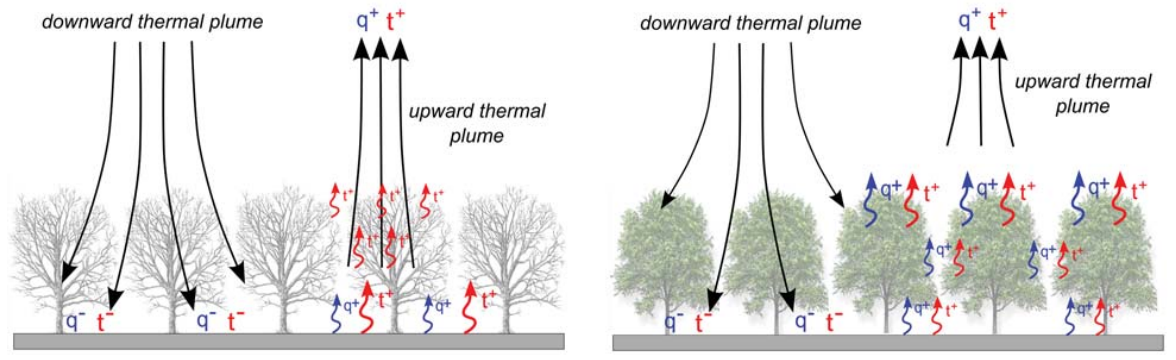

(b) Near-neutral regime
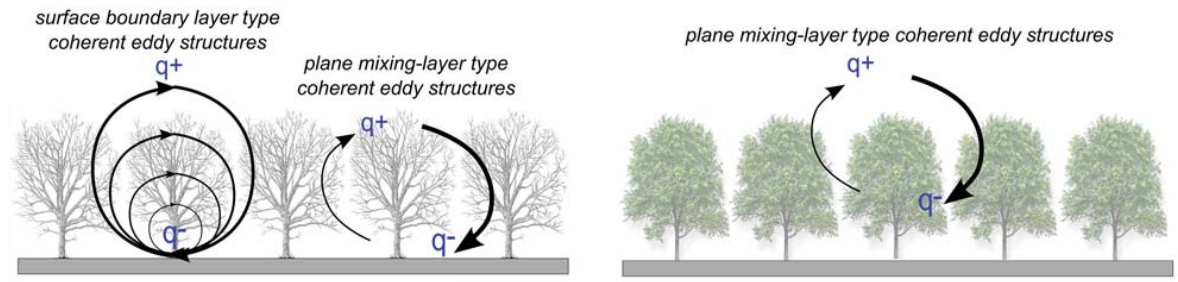

(c) Stable regime
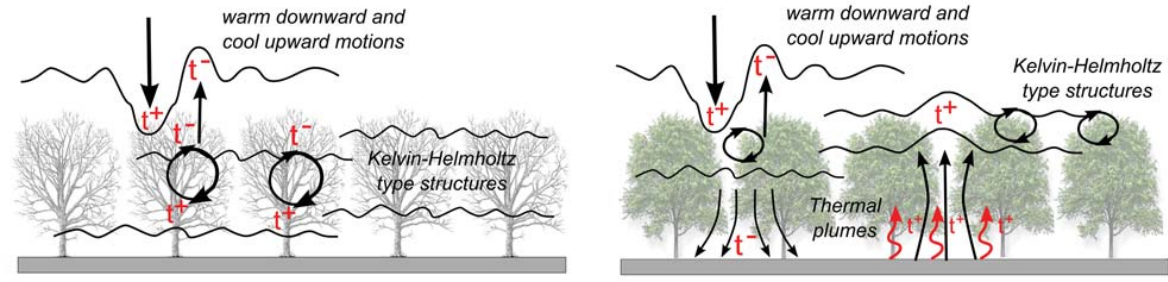

Without leaves

With leaves

Fig. 12. Idealized representation of the turbulent structures transporting momentum and scalars (temperature $t$ and water vapor $q$ ) at CHATS and their main characteristics during: (a) free convection, (b) near-neutral, and (c) stable regimes for both seasonal periods (without and with leaves).

same characteristic found above the canopy. However, when the scalar is imparted to the flow in a distributed fashion through the canopy (e.g. water vapor in the foliated period, or temperature during either period), downward motions dominate within-canopy transport eventhough upward motions still contribute more to above-canopy scalar transport. Therefore, in free convective conditions (light winds) the scalar source location and that scalar's dominant role in generating vertical motions explains the reduced correlation coefficient between heat and water vapor fluxes during the period with no-leaves. Heat and water vapor are therefore transported differently during this period, with water vapor probably transported mostly by inactive large scale motions like the longitudinal wind velocity and to a lesser extent by thermal plumes developing at the ground.

The release of heat and water vapor by vegetation is not continuous and depends on numerous environmental factors. Scalar sources should increase with the gradient between the surface and the surrounding air as well as with increasing wind velocity via the exchange coefficient. Therefore, downward thermal plumes carrying depleted scalar concentrations should enhance the scalar source. When these plumes pass through the scalar source region, the scalar quantity transported by the plumes should therefore change. However, the CHATS observations show that scalars carried by downward plumes are not modified when passing through the elevated scalar source region (Sect. 5.1). The only explanation for this discrepancy could be a time delay between the plume's passage and the plant's response, a feature which is well known for water vapor (through stomatal time response; Jones, 1992) but not for heat. Hence why we suggest that scalars are preferentially emitted into local upward plumes. This process is certainly only true when scalar sources are co-located with heat sources. This finding may impact scalar source modeling within large-eddy simulations (LESs) since upward and 
downward thermal plumes are explicitly resolved by these models.

Finally, for this stability regime the canopy appears fully coupled with the overlying atmosphere as warm-upward and cool-downward thermal plumes significantly contribute to the exchange of heat and water vapor. This finding is consistent with the "fully coupled canopy" regime observed by Thomas and Foken (2007a) over a tall spruce canopy during afternoon. However, the coupling strength differs across scalars due to the source-location influence on scalar transport efficiency. For other trace gases, this finding could have some implications regarding the residence times of these gases since surface emitted species are apparently transported less efficiently within the canopy layers than species emitted in a distributed fashion through the canopy depth, suggesting longer within-canopy residence times for surfaceemitted species.

\subsection{Near-neutral regime}

Dupont and Patton (2012) found that the plane mixinglayer analogy explains turbulent flow within and above the CHATS canopy better during the foliated period than during the defoliated period. Finnigan et al. (2009) proposed that these mixing-layer structures are comprised of a linked pair of hairpin vortices; i.e. a combination of an ejectionproducing head-up and a sweep-producing head-down, with the head-down vortex dominating at canopy-top due to rapid straining and preferential vorticity amplification associated with downward deflections. Resulting from the defoliated canopy's sparseness, sweep and ejection motions responsible for transporting momentum and scalar constituents may be a combination of mixing-layer type coherent structures developing below canopy top superposed with surface-layer type structures whose length scales vary with distance from the surface. Although, the mixing-layer structures dominating exchange during the foliated period transport these quantities more efficiently. This superposition of turbulent structures within canopy was suggested by Poggi et al. (2004) and Kobayashi and Hiyama (2011), and deduced in the orchard canopy from the spectral analysis of the wind velocity components (Dupont and Patton, 2012) .

\subsection{Stable regime}

In this regime, within-canopy micrometeorology and turbulent exchange differ substantially across seasonal periods due to the well-defined unstable layer in the lower canopy during the foliated period.

During the no-leaves period, turbulent exchanges appear similar to that of stable surface-layers, but with potential development of either Kelvin-Helmholtz instabilities or gravity waves in the upper canopy; although, not fully developing into mixing-layer type coherent structures like those in the near-neutral regime likely as a result of the canopy-top gradient Richardson number exceeding the critical value of 0.25 . Initiation of these instabilities could be related to intermittent warm and dry downward motions associated with residual elevated shear layers or low level jets (Mahrt, 1999). In response, cool and humid upward motions develop but may not be as well defined as the downward motions. These instabilities could then propagate into the canopy airspace, as recently observed by van Gorsel et al. (2011) over open canopies. For this seasonal period, the exchange regime corresponds to the "wave motion" regime defined by Thomas and Foken (2007a), which occurs mostly at night, particularly just before sunrise.

During the foliated period, scalar turbulent exchanges in the lower CHATS canopy occur mostly through thermal plumes. Upward thermal plumes may act to perturb the flow at canopy top, generating instabilities or gravity waves; intermittent downward motions from above can act similarly. Hence, during the foliated period, two types of turbulent structures may coexist within the canopy, small and intermittent "shear-driven" coherent eddy structures at canopy top and "buoyantly-driven" coherent structures in the lower canopy. Both structures may stay confined in their region of development, inducing a decoupling between the lower and the upper canopy. Canopy-top instabilities may propagate within the canopy but do not contribute to scalar transport; which explains why autocorrelation contours of $u$ and $w$ centered at canopy-top extend deeper within the canopy than those of $t$ and $q$. Hence, for this seasonal period the exchange regime still corresponds to the "wave motion" regime although turbulent exchanges exist but they stay confined within the subcanopy.

Although gravity waves were not investigated in the present study, they were observed above the orchard canopy during both seasonal periods by Jachens and Mayor (2012) with a Raman-shifted Eye-safe Aerosol Lidar.

\subsection{Intermediate stability regimes}

The forced convection regime (FoC) should be seen as an intermediate regime between the near-neutral $(\mathrm{NN})$ and free convection $(\mathrm{FrC})$ regimes with the possible superposition of: (i) "shear-driven" structures, mixing-layer type structures developing in the upper canopy and surface boundary-layer type structures if the canopy is sparse, and (ii) "buoyantlydriven" structures, or thermal plumes. With increasingly unstable conditions, it is not clear whether there is a distinct superposition of different structure types, or if "shear-driven" structures become progressively "buoyantly-driven" structures. Hommema and Adrian (2003) observed from smoke visualization that in an unstable surface boundary layer turbulent structures lift off the surface. They postulated that these structure correspond to the superposition of a "sheardriven" structure and a buoyant upward motion.

In the transition to stable regime (TS) at CHATS, an unstable layer progressively develops in the lower canopy during 
the foliated period and plane mixing-layer type structures becomes smaller, less frequent and should look more like Kelvin-Helmholtz type structures; a result of decreased ambient turbulence levels.

\section{Concluding remarks}

From this CHATS data analysis, a detailed schematic picture of momentum, heat, and water vapor transport mechanisms is presented and their associated turbulent structures over a vegetated canopy following the atmospheric stability at canopy top and the canopy's seasonal state (Fig. 12). This analysis suggests that the canopy's seasonal state plays a vital role in determining the turbulent transport processes coupling the canopy layers with the overlying atmosphere. In near-neutral stability (NN), traditional mixing-layer type structures dominate turbulent scalar transport when there are leaves on the trees. While in the absence of leaves, canopy exchange appears to occur through a combination of these mixing-layer structures superposed with surface layer type structures.

Although the vegetation's branches and trunks impose heat sources during both seasonal periods, during the foliated period the leaves dramatically modify the vertical temperature distribution across stability ranges through their low heat capacity, ability to regulate their own temperature through transpiration, and tendency to absorb/scatter solar radiation and to absorb/emit thermal radiation. With departure from near-neutral conditions, the sweep/ejection motions associated with mixing-layer type turbulent structures no longer dominate canopy exchange. Rather, turbulent scalar exchange occurs through thermal plumes during unstable conditions. During stable conditions, elevated radiational cooling of the exposed leaves in the upper canopy generates downwelling thermal plumes in the lower canopy; a feature not present during the defoliated period, and which is of critical importance in controlling within-canopy chemical processing of biogenic or surface-emitted reactive species.

Some turbulent exchange processes remain ambiguous and require further study: (i) in unstable conditions, the link between local thermal plumes generated by the vegetation elements and large scale convective plumes above the canopy, (ii) the coupling between these locally generated thermal plumes and scalar source strength/location, and (iii) in stable conditions, the origin and development of intermittent instabilities in the upper canopy.

\section{Supplementary material related to this article is available online at: http://www.atmos-chem-phys.net/12/ 5913/2012/acp-12-5913-2012-supplement.pdf.}

Acknowledgements. This work was conducted at the National Center for Atmospheric Research (NCAR), Boulder, CO, USA. Sylvain Dupont was supported by the Institut National de Recherche Agronomique (INRA) through its long term mission program, and by the program "PEDO COTESOF" of the Agence Nationale de la Recherche (ANR). Edward Patton was supported by NCAR's Bio-hydro-atmosphere interactions of Energy, Aerosols, Carbon, $\mathrm{H}_{2} \mathrm{O}$, Organics \& Nitrogen (BEACHON) project and by the Army Research Office (Grant No.: W911NF-09-1-0572) under subcontract from the University of Colorado, Boulder. We would like to thank: (i) Drs. M. Böhm, S. P. Burns, B. A. Gardiner, J. J. Finnigan, I. N. Harman, T. W. Horst, R. H. Shaw, P. P. Sullivan, J. C. Weil, and E. van Gorsel for helpful discussions, (ii) the Cilker family for their interest and willingness to allow CHATS to take place at Cilker Orchards, and (iii) the individuals and sponsors who collaborated on bringing CHATS to fruition, with special thanks to the NCAR EOL staff who worked tirelessly to ensure the quality and success of the campaign. NCAR is sponsored in part by the National Science Foundation. Finally, we thank the two anonymous reviewers for their helpful comments.

Edited by: T. Karl

\section{References}

Adrian, R. J.: Hairpin vortex organization in wall turbulence, Phys. Fluids, 19, 041301, doi:10.1063/1.2717527, 2007.

Baldocchi, D. and Meyers, T.: A spectral and lag-correlation analysis of turbulence in a deciduous forest canopy, Bound.-Lay. Meteorol., 45, 31-58, 1988.

Böhm, M., Harman, I., Van Gorsel, E., Finnigan, J., Raupach, M., Vogt, R., and Christen, A.: Identification of processes governing within-canopy momentum and scalar transfer from vegetation canopies to urban landscapes, in: Proc. of the Amer. Meteorol. Soc. 19th Symp. on Bound.-Layers and Turb., Abstract J5.3, 1-6 August 2010, Keystone, CO, USA, 2010.

Bohrer, G., Katul, G. G., Walko, R. L., and Avissar, R.: Exploring the effects of microscale structural heterogeneity of forest canopies using large-eddy simulations, Bound.-Lay. Meteorol., 132, 351-382, 2009.

Brunet, Y. and Irvine, M. R.: The control of coherent eddies in vegetation canopies: streamwise structure spacing, canopy shear scale and atmospheric stability, Bound.-Lay. Meteorol., 94, 139-163, 2000.

Cava, D. and Katul, G.: Spectral short-circuiting and wake production within the canopy trunk space of an alpine hardwood forest, Bound.-Lay. Meteorol., 126, 415-431, 2008.

Chen, F.: Turbulent characteristics over a rough natural surface. 2. Responses of profiles to turbulence, Bound.-Lay. Meteorol., 52, 301-311, doi:10.1007/BF00122092, 1990.

Collineau, S. and Brunet, Y.: Detection of turbulent coherent motions in a forest canopy. 1. Wavelet analysis, Bound.-Lay. Meteorol., 65, 357-379, 1993a.

Collineau, S. and Brunet, Y.: Detection of turbulent coherent motions in a forest canopy. 2. Time-scales and conditional averages, Bound.-Lay. Meteorol., 66, 49-73, 1993b.

Coppin, P. A., Raupach, M. R., and Legg, B. J.: Experiments on scalar dispersion within a model-plant canopy. 2. An el- 
evated plane source, Bound.-Lay. Meteorol., 35, 167-191, doi:10.1007/BF00117307, 1986.

Dupont, S. and Brunet, Y.: Influence of foliar density profile on canopy flow: a large-eddy simulation study, Agr. Forest Meteorol., 148, 976-990, 2008.

Dupont, S., Bonnefond, J.-M., Irvine, M. R., Lamaud, E., and Brunet, Y.: Long-distance edge effects in a pine forest with a deep and sparse trunk space: In situ and numerical experiments, Agr. For. Meteorol., 151, 328-344, 2011.

Dupont, S. and Patton, E. G.: Influence of thermal stability and seasonal canopy changes on micrometeorology within and above an orchard canopy: The CHATS experiment, Agric. Forest Meteorol., 157, 11-29, 2012.

Dupont, S., Irvine, M. R., Bonnefond, J.-M., Lamaud, E., and Brunet, Y.: Turbulent structures within a pine forest with a large and sparse trunk space: stand and edge conditions, Bound.-Lay. Meteorol., 143, 309-336, 2012.

Finnigan, J. J.: Turbulence in waving wheat. II. Structure of momentum transfer, Bound.-Lay. Meteorol., 16, 213-236, 1979.

Finnigan, J. J.: Turbulence in plant canopies, Ann. Rev. Fluid Mech., 32, 519-571, 2000.

Finnigan, J. J., Shaw, R. H., and Patton, E. G.: Turbulence structure above a vegetation canopy, J. Fluid Mech., 637, 387-424, 2009.

Gao, W., Shaw, R. H., and Paw U, K. T.: Observation of organised structures in turbulent flow within and above a forest canopy, Bound.-Lay. Meteorol., 47, 349-377, 1989.

Gates, D. and Benedict, C.: Convection phenomena from plant in still air, Am. J. Bot., 50, 563-573, 1963.

Ghisalberti, M. and Nepf, H. M.: Mixing layers and coherent structures in vegetated aquatic flows, J. Geophys. Res.-Oceans, 107, 3011, doi:10.1029/2001JC000871, 2002.

van Gorsel, E., Böhm, M., Harman, I., Finnigan, J., Christen, A., and Vogt, R.: Effects of diabatic stability on turbulent biosphereatmosphere exchange processes for momentum and scalars, in: Proc. of the Amer. Meteorol. Soc. 19th Symp. on Bound.-Layers and Turb., Abstract J8.6, 1-6 August 2010, Keystone, CO, USA, 2010.

van Gorsel, E., Harman, I. N., Finnigan, J. J., and Leuning, R.: Decoupling of air flow above and in plant canopies and gravity waves affect micrometeorological estimates of net scalar exchange, Agr. Forest Meteorol., 151, 927-933, 2011.

Harman, I. N.: The role of roughness sublayer dynamics within surface exchange schemes, Bound.-Lay. Meteorol., 142, 1-20, 2012.

Hommema, S. E. and Adrian, R. J.: Packet structure of surface eddies in the atmospheric boundary layer, Bound.-Lay. Meteorol., 106, 147-170, doi:10.1023/A:1020868132429, 2003.

Jachens, E. R. and Mayor, S. D.: LIDAR observation of fine-scale atmospheric gravity waves in the nocturnal boundary layer above an orchard canopy, in: Proc. of 26th International Laser radar Conference (ILRC), 25-29 June 2012, Porto Heli, Greece, 2012.

Jacobs, A. F. G., Van Boxel, J. H., and El-Kilani, M. M.: Nighttime free convection characteristics within a plant canopy, Bound.Lay. Meteorol., 71, 375-391, 1994.

Jones, H.: Plants and microclimate, a quantitative approach to environmental plant physiology, 2nd edition, Cambridge University Press, New York, NY 10011-4211, USA, 1992.

Kanda, M. and Hino, M.: Organized structures in developing turbulent-flow within and above a plant canopy using a large- eddy simulation, Bound.-Lay. Meteorol., 68, 237-257, 1994.

Katul, G., Kuhn, G., Schieldge, J., and Hsieh, C. I.: The ejection-sweep character of scalar fluxes in the unstable surface layer, Bound.-Lay. Meteorol., 83, 1-26, doi:10.1023/A:1000293516830, 1997.

Kobayashi, N. and Hiyama, T.: Stability dependence of canopy flows over a flat larch forest, Bound.-Lay. Meteorol., 139, $97-$ 120, doi:10.1007/s10546-010-9572-2, 2011.

Launiainen, S., Vesala, T., Mölder, M., Mammarella, I., Smolander, S., Rannik, U., Kolari, P., Hari, P., Lindroth, A., and Katul, G. G.: Vertical variability and effect of stability on turbulence characteristics down to the floor of a pine forest, Tellus B, 59, 919-936, 2007.

Li, D. and Bou-Zeid, E.: Coherent structures and the dissimilarity of turbulent transport of momentum and scalars in the unstable atmospheric surface layer, Bound.-Lay. Meteorol., 140, 243-262, doi:10.1007/s10546-011-9613-5, 2011.

Lu, C. H. and Fitzjarrald, D. R.: Seasonal and diurnal variations of coherent structures over a deciduous forest, Bound.-Lay. Meteorol., 69, 43-69, 1994.

Fitzmaurice, L., Shaw, R. H., Paw U, K. T., Patton, E. G.: Threedimensional scalar microfront systems in a large-eddy simulation of vegetation canopy flow, Bound.-Lay. Meteorol., 112, 107227, doi:10.1023/B:BOUN.0000020159.98239.4a, 2004.

Mahrt, L.: Stratified atmospheric boundary layers, Bound.-Layer Meteorol., 90, 375-396, 1999.

Maitani, T. and Ohtaki, E.: Turbulent transport processes of momentum and sensible heat in the surface-layer over a paddy field, Bound.-Lay. Meteorol., 40, 283-293, doi:10.1007/BF00117452, 1987.

Moene, A. F., Michels, B. I., and Holtslag, A. A. M.: Scaling variances of scalars in a convective boundary layer under different entrainment regimes, Bound.-Lay. Meteorol., 120, 257-274, doi:10.1007/s10546-006-9053-9, 2006.

Moriwaki, R. and Kanda, M.: Local and global similarity in turbulent transfer of heat, water vapour, and $\mathrm{CO}_{2}$ in the dynamic convective sublayer over a suburban area, Bound.-Lay. Meteorol., 120, 163-179, doi:10.1007/s10546-005-9034-4, 2006.

Patton, E. G., Davis, K. J., Barth, M. C., and Sullivan, P. P.: Decaying scalars emitted by a forest canopy: a numerical study, Bound.-Lay. Meteorol., 100, 91-129, 2001.

Patton, E. G., Horst, T. W., Sullivan, P. P., Lenschow, D. H., Oncley, S. P., Brown, O. J., Burns, S. P., Guenther, A. B., Held, A., Karl, T., Mayor, S. D., Rizzo, L. V., Spuler, S. M., Sun, J., Turnipseed, A., Allwine, E. J., Edburg, S. L., Lamb, B. K., Avissar, R., Calhoun, R. J., Kleissl, J., Massman, W. J., Paw U, K. T., and Weil, J. C.: The canopy horizontal array turbulence study, B. Am. Meteorol. Soc., 92, 593-611, 2011.

Paw U, K. T., Brunet, Y., Collineau, S., Shaw, R. H., Maitani, T., Qiu, J., and Hipps, L.: On coherent structures in turbulence above and within agricultural plant canopies, Agr. Forest Meteorol., 61, 55-68, 1992.

Poggi, D., Porporato, A., Ridolfi, L., Albertson, J. D., and Katul, G. G.: The effect of vegetation density on canopy sublayer turbulence, Bound.-Lay. Meteorol., 111, 565-587, 2004.

Poggi, D., and Katul, G. G.: The effect of canopy roughness density on the constitutive components of the dispersive stresses, Exp. Fluids, 45, 111-121, 2008. 
Qiu, J., Paw U, K. T., and Shaw, R. H.: Pseudo-wavelet analysis of turbulence patterns in three vegetation layers, Bound.-Lay. Meteorol., 72, 177-204, 1995.

Raupach, M. R., Finnigan, J. J., and Brunet, Y.: Coherent eddies and turbulence in vegetation canopies: the mixing-layer analogy, Bound.-Lay. Meteorol., 78, 351-382, 1996.

Scanlon, T. M. and Alberston, J. D.: Turbulent transport of carbon dioxide and water vapor within a vegetation canopy during unstable conditions: identification of episodes using wavelet analysis, J. Geophys. Res., 106, 7251-7262, 2001.

Schmidt, H. and Schumann, U.: Coherent structure of the convective boundary layer derived from large-eddy simulation, J. Fluid Mech., 200, 511-562, 1989.

Shaw, R. H. and Schumann, U.: Large-eddy simulation of turbulent flow above and within a forest, Bound.-Lay. Meteorol., 61, 4764, doi:10.1007/BF02033994, 1992.

Shaw, R. H., Tavangar, J., and Ward, D. P.: Structure of the Reynolds stress in a canopy layer, J. Clim. Appl. Meteorol., 22, 19221931, 1983.

Shaw, R. H., den Hartog, G., and Neumann, H. H.: Influence of foliar density and thermal-stability on profiles of Reynolds stress and turbulence intensity in a deciduous forest, Bound.-Lay. Meteorol., 45, 391-409, doi:10.1007/BF00124010, 1988.

Shaw, R. H., Brunet, Y., Finnigan, J. J., and Raupach, M. R.: A wind tunnel study of air flow in waving wheat: two-point velocity statistics, Bound.-Lay. Meteorol., 76, 349-376, 1995.

Steiner, A. L., Pressley, S. N., Botros, A., Jones, E., Chung, S. H., and Edburg, S. L.: Analysis of coherent structures and atmospheric-canopy coupling strength during the CABINEX field campaign, Atmos. Chem. Phys., 11, 11921-11936, doi:10.5194/acp-11-11921-2011, 2011.
Su, H. B., Shaw, R. H., and Paw U, K. T.: Two-point correlation analysis of neutrally stratified flow within and above a forest from large-eddy simulation, Bound.-Lay. Meteorol., 94, 423460, 2000.

Thomas, C. and Foken, T.: Flux contribution of coherent structures and its implications for the exchange of energy and matter in a tall spruce canopy, Bound.-Lay. Meteorol., 123, 317-337, 2007a.

Thomas, C. and Foken, T.: Organised motion in a tall spruce canopy: temporal scales, structure spacing and terrain effects, Bound.-Lay. Meteorol., 122, 123-147, 2007b.

Turner, B. J., Leclerc, M. Y., Gauthier, M., Moore, K. E., and Fitzjarrald, D. R.: Identification of turbulence structures above a forest canopy using a wavelet transform, J. Geophys. Res.-Atmos., 99, 1919-1926, 1994.

Watanabe, T.: Large-eddy simulation of coherent turbulence structures associated with scalar ramps over plant canopies, Bound.Layer Meteorol., 112, 307-341, 2004.

Williams, C. A., Scanlon, T. M., and Albertson, J. D.: Influence of surface heterogeneity on scalar dissimilarity in the roughness sublayer, Bound.-Layer Meteorol., 122, 149-165, doi:10.1007/s10546-006-9097-x, 2007.

Willmarth, W. W. and Lu, S. S.: Structure of the Reynolds stress near the wall, J. Fluid Mech., 55, 65-92, 1972.

Wyngaard, J. C. and Brost, R. A.: Top-down and bottom-up diffusion of a scalar in the convective boundary layer, J. Atmos. Sci., 41, 102-112, 1984. 